\title{
On Three Monostiliferous Hoplonemerteans from the San Juan Archipelago, Washington State, USA
}

$\operatorname{AUTHOR}(\mathrm{S}):$

IWATA, Fumio

\section{CITATION:}

IWATA, Fumio. On Three Monostiliferous Hoplonemerteans from the San Juan Archipelago, Washington State, USA. Publications of the Seto Marine Biological Laboratory 2008, 40(5-6): 9-45

ISSUE DATE:

2008-04-30

URL:

http://hdl.handle.net/2433/72819

RIGHT: 


\title{
On Three Monostiliferous Hoplonemerteans from the San Juan Archipelago, Washington State, USA
}

\author{
Fumio IwATA \\ Laboratory of Biology, Momijidai, Nishi 5-9-13, Atsubetsu-ku, Sapporo 004-0013, Japan \\ E-mail: fumiwata@d6.dion.ne.jp
}

\begin{abstract}
The descriptions of Amphiporus formidabilis Griffin, A. imparispinosus Griffin, and Nipponnemertes punctatula (Coe), all known to occur in the eastern North Pacific, are revised on the basis of re-observation of their morphological features. The significant characters are explained.
\end{abstract}

Key words: Nemertea, Monostilifera, Amphiporus, Nipponnemertes

\section{Introduction}

The present paper deals with three species of monostiliferous hoplonemerteans collected in the San Juan Archipelago, Washington state, USA in 1964. Two were originally described as Amphiporus formidabilis Griffin, 1898 and A. imparispinosus Griffin, 1898; the third was originally described as Amphiporus punctatulus Coe, 1905, later became the type species of the genus Nipponnemertes (Crandall, 2001). Specimens were fixed in Bouin's solution after anesthetized by addition of menthol or $70 \%$ alcohol. Two specimens of both Amphiporus species and two specimens of N. punctatula were sectioned at $8 \mu \mathrm{m}$ and stained with Delafield's hematoxylin and eosin. A Sony video camera with Symphonic monitor television and Sony color video printer, in addition to an Olympus BH-2 microscope, were used for observation of the material.

\section{Results}

Taxonomy

Class Enopla

Order Hoplonemertea

Suborder Monostilifera

Family Amphiporidae

1. Amphiporus formidabilis Griffin

2. Amphiporus imparispinosus Ghriffin

Family Cratenemertidae

3. Nipponnemertes punctatula $(\mathrm{Coe})$

\section{Description of species}

\section{Amphiporus formidabilis Griffin, 1898}

(Pl. 1, fig. 1; Fig. 1a; Figs. 2-7; Tables 1 and 2)

Amphiporus formidabilis Griffin, 1898: p. 211, figs. 21-22; Coe, 1905: p. 250-252, pl. 17, figs.101,102, text-figs.13,15, 23, 54; Iwata, 1952;

p. 144-146, text-figs. 15, 16; Correa, 1964: p. 544-545; Gibson, 1995: p. 283.

Amphiporus exilis Coe, 1901: p. 54-56, pl. 3, fig. 1, pl. 7, fig. 5, pl. 11, fig. 3; Gibson, 1995: p. 282. 
Specific diagnosis

Pale whitish blue, without pattern; with a transverse cephalic furrow; numerous small eyes (98) in four groups; six accessory stylet pouches; proboscis with 26 or 30 nerves; subepithelial glands present in anterior portion of body; intestinal caecum with a pair of anterior diverticula and 15 pairs of lateral diverticula; central stylet-basis with bolster composed of circular muscles; efferent ducts numerous, 18 in the right side of the body and nine in the left side.

\section{Material}

Six specimens are deposited in the National Museum of Natural History, Smithsonian Institution, Washington, DC, USA

One specimen (female) consisting of 33 slides of stained serial sections, including nine slides of the head region, 18 slides of the middle portion, six slides of the posterior region, and a piece of the posterior region that was not sectioned.

One specimen (male) consisting of 20 slides of a stained serial sections of the head region and a long piece of the posterior region that was not sectioned.

\section{Locality}

Eight specimens collected at low tide on the shore between Deadman Bay and Pile Point, San Juan Island Washington State, USA on September 3, 1964.

\section{External features}

One specimen was about $15 \mathrm{~cm}$ long by $1.2 \mathrm{~mm}$ wide (Pl. 1, fig. 1). It was slender and pale whitish blue, but in the region of the foregut it was pale orange. It had numerous light brown spots on the dorsal surface and the proboscis and stylets were visible. The head was expanded into the shape of a fan and was wider than the esophageal region; it was also well marked off, by a transverse cephalic furrow, from the part following (Fig. 1a). The furrow encircled the neck, forming a $\mathrm{V}$ on the dorsal surface, but on the ventral surface it formed a straight transverse line. In this specimen, anterior furrows on the dorsal surface were not observed. The total number of eyes in the two anterior clusters was at least 31 . There were at least 34 eyes in the posterior group, whose right and left clusters converged anteriorly to form a $\mathrm{V}$; the posterior edges of these clusters reached nearly to the brain (Fig. 1a). The two posterior groups met on the midline (Fig. 1a).

The eyes of six specimens collected at San Juan Island were recorded in the Table 1, showing that

Table 1. The eyes of Amphiporus formidabilis counted on six specimens collected at San Juan Island.

\begin{tabular}{ccccc}
\hline \multicolumn{4}{c}{ Anterior group } & \multicolumn{4}{l}{ Posterior group } \\
\hline Left & Right & Left & Right & Total \\
\hline 18 & 13 & 19 & 15 & 65 \\
20 & 20 & 29 & 29 & 100 \\
17 & 17 & 34 & 38 & 106 \\
24 & 25 & 40 & 40 & 129 \\
25 & 22 & 43 & 42 & 132 \\
30 & 31 & 40 & 45 & 146 \\
\hline
\end{tabular}


the average total number of eyes was 113 .

Body wall, musculature, and parenchyma

The epidermis is of uniform thickness in both the cephalic region (average $35 \mu \mathrm{m}$ ) and in the middle region (average $50 \mu \mathrm{m}$ ). Large unicellular glands are lacking. Slender columnar glands are thickly scattered in the cephalic region, where they are separated into upper vacuolated and lower cytoplasmic portions. Large glands are arranged in the middle portion of the body and no small eosinophil glands are found here.

Near the anterior end of the head, between the tip and the proboscis pore, a median groove can be seen in transverse sections.

The dermis is $15 \mu \mathrm{m}$ thick and one-third as thick as the epidermis. It has transverse fibrils but contains no cellular bodies or small nerves. Subepithelial glands, found in members of Paranemertes,

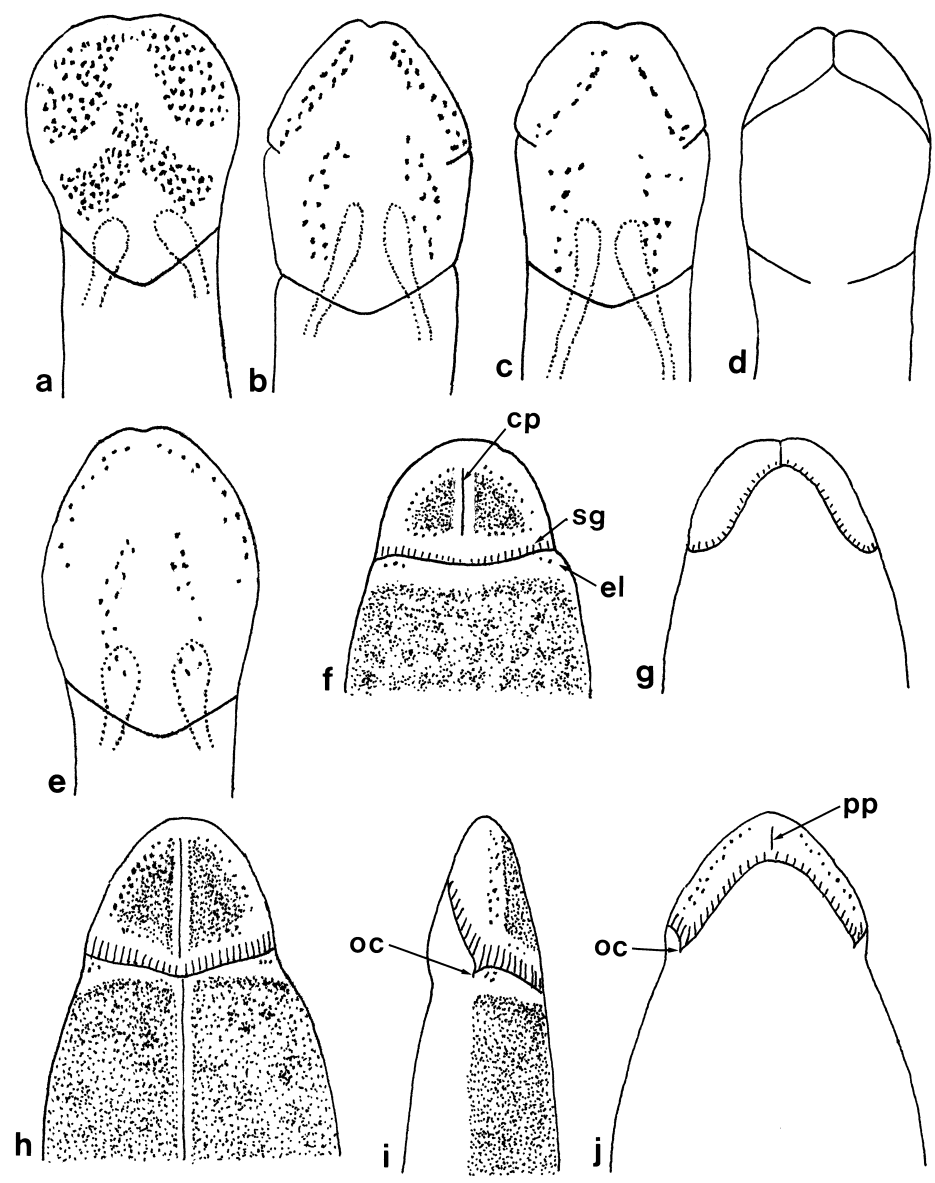

Fig. 1. Amphiporus formidabilis. (a), anterior portion, dorsal view; (b-e), Amphiporus imparispinosus anterior portion, dorsal view (b, c, e) and ventral view (d); (f-j), Nipponnemertes punctatula. (f) dorsal and (g) ventral views of specimen collected at Mineral Point, San Juan Island; (h) dorsal, (i) lateral, and (j) ventral views of specimen collected in San Juan Channel; $\mathrm{cp}=$ cephalic groove ; oc = opening of cerebral organ; $\mathrm{el}=$ eye behind cephalic furrow; $\mathrm{pp}=$ proboscis pore; $\mathrm{sg}=$ sagittally-ridged secondary cephalic grooves. 
are lacking. The body wall musculature consists of an outer circular coat and inner longitudinal layer, and there is a diagonal muscle layer: on the dorsal side of the body in the pyloric region (Fig. 2a), the circular and longitudinal layers are, respectively, $25 \mu \mathrm{m}$ and $50 \mu \mathrm{m}$ thick.

Near the posterior end of the brain, the longitudinal muscle layer of the body wall becomes divided into inner and outer layers, these separated by parenchyma (Fig. 3c). The outer layer continues into the tip of the head without contributing to the proboscis insertion; a pre-cerebral septum is lacking. The inner layer consists of flattened bundles with surrounding membranes; these bundles are arranged outside the proboscis sheath at the dorsal side of the body and the brain, forming a closed cylinder covering the brain and the esophagus (Figs. 3c, d, 4f, 6b-d, g). In the mid-dorsal portion of the body, at the level where the inner longitudinal muscles are separated, there are no circular muscle fibers extending obliquely from the circular muscle layer of the body wall (Fig. 3c).

Dorsoventral and horizontal muscles are lacking. Parenchyma is well-developed between the body wall musculature and the rhynchocoel above the intestinal diverticula.

Rhynchodeum, rhynchocoel, and proboscis

The proboscis pore, $240 \mu \mathrm{m}$ long, $160 \mu \mathrm{m}$ wide, opens into the narrow median deep groove (160 $\mu \mathrm{m}$ deep) on the ventral side of the head (Fig. 2b). Its wall is $15 \mu \mathrm{m}$ thick and has cilia but no glands. The rhynchodeum between the end of the proboscis pore and the mouth is $370 \mu \mathrm{m}$ long, and in transverse sections it has a flattened cavity (200 $\mu \mathrm{m}$ wide by $40 \mu \mathrm{m}$ high) (Fig. 2c). The wall of the rhynchodeum consists of flattened cells (15 $\mu \mathrm{m}$ thick) that have cilia but that are not glandular.

Posteriorly, flattened cavity of the rhynchodeum becomes oval (100 $\mu \mathrm{m}$ high by $190 \mu \mathrm{m}$ wide) (Fig. 2d) and then triangular (120 $\mu \mathrm{m}$ high by $110 \mu \mathrm{m}$ wide) just before the mouth (Fig. 2e). The triangular cavity is covered by an inner epithelium, a thick layer of circular muscles of the rhynchodeal sphincter, and an outer thin layer of longitudinal fibers which are derived from the inner longitudinal muscle of the body wall; ventrally it is covered by the inner epithelium and the foregut wall (Fig. 2d, e). It is elongated dorsoventrally and the mouth appears on its ventral side (Fig. 2f-h). The rhynchodeum above the esophagus consists of an inner epithelium, the rhynchodeal sphincter, and a thin layer of longitudinal muscle fibers; these layers, respectively, are $130 \mu \mathrm{m}, 30 \mu \mathrm{m}$, and $10 \mu \mathrm{m}$ thick (Figs. 2h, 3a). The rhynchodeum extends $140 \mu \mathrm{m}$ anterior to the dorsal commissure of the brain, where the proboscis insertion is located dorsally (Fig. 3b).

At the proboscis insertion, the rhynchodeum wall, consisting of the inner epithelium and the outer rhynchodeal sphincter, is transformed into the following components of the proboscis apparatus: epithelium, circular and longitudinal muscle layers (containing 26 or 30 proboscis nerves), rhynchocoel, and proboscis sheath, which consists of longitudinal and circular muscle layers (Fig. 2a).

The transformation of the rhynchodeum wall at the proboscis insertion, $60 \mu \mathrm{m}$ long, occurs just before the dorsal commissure of the brain (Fig. 3b, d) and inside the ganglia, where the inner longitudinal muscles enter through the anterior end of the brain and the lateral sides of the esophagus (Figs. 3e, 6h). Precerebrally, the inner longitudinal muscles are developed in a thin layer, $130 \mu \mathrm{m}$ long, encircling the rhynchodeum wall, extending anteriorly over the junction with the esophagus up to the portion where the rhynchodeum becomes oval (Figs. 2c-h, 3a). The distance between the posterior end of the inner longitudinal muscle of the body wall and the dorsal commissure of the brain, where the proboscis insertion occurs, is $130 \mu \mathrm{m}$ long.

There are head-retractor muscles derived from the outer longitudinal muscle layer of the body wall.

The rhynchocoel has circular and longitudinal muscle layers and ends a little anterior to the posterior nerve anastomosis (Fig. 2a).

The proboscis diaphragm has a central stylet with a massive basis, this being about $0.3 \mathrm{~mm}$ long (Fig. 3f). The central stylet, which had been moved outside the basis, was $80 \mu \mathrm{m}$ long and surrounded by a cellular mass (Fig. 3g). A stylet found in an accessory stylet pouch has the same length as the central stylet (Fig. $3 \mathrm{~h}$ ). The basis, $0.11 \mathrm{~mm}$ in diameter in its lower portion, has an 

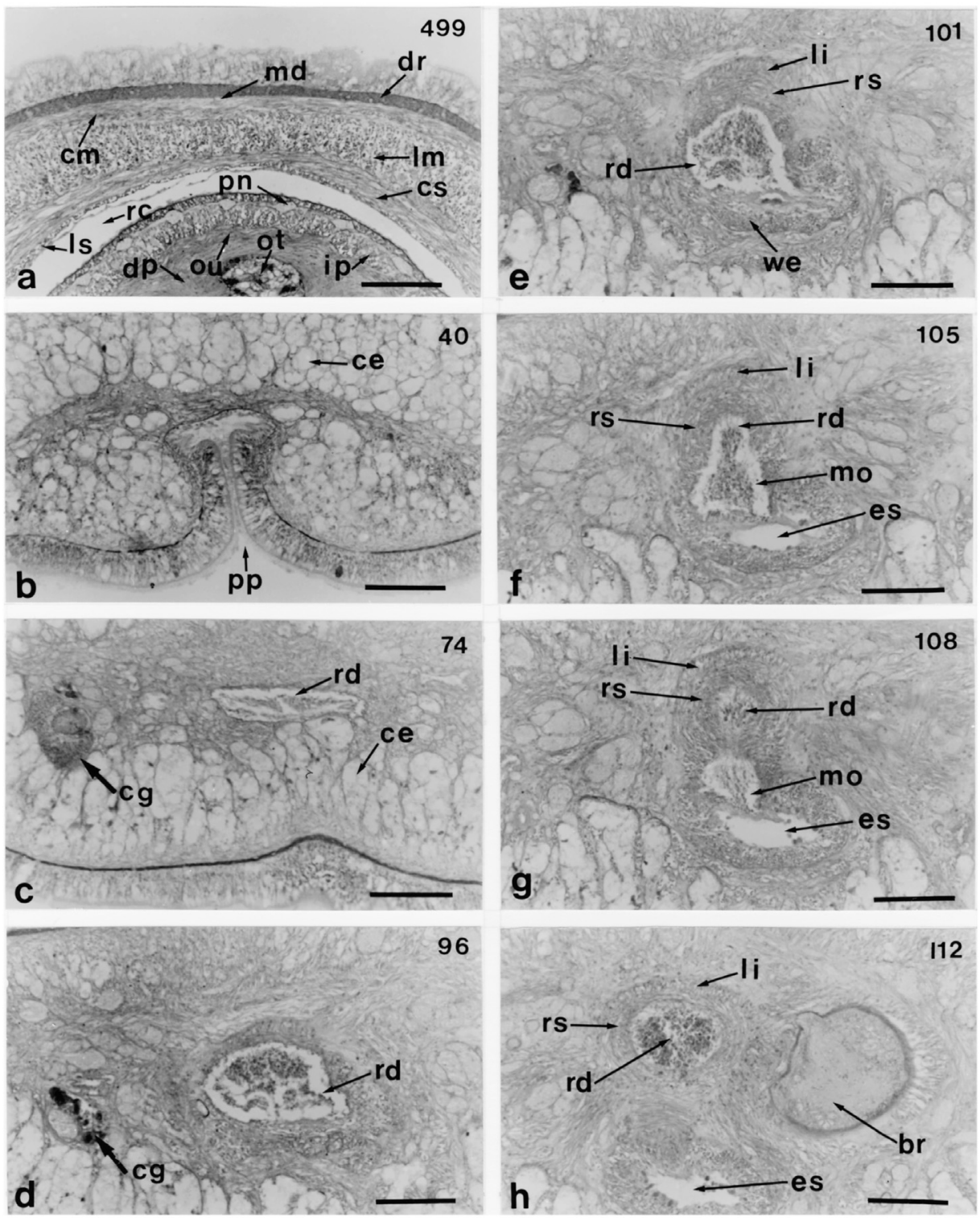

Fig. 2. Amphiporus formidabilis. Transverse sections between 40-499 from anterior end of body, showing (a) construction of body wall, proboscis sheath, and proboscis, (b) proboscis pore, (c) rhynchodeum, (d) rhynchodeum thickened dorsoventrally, (e) rhynchodeum just before the mouth, (f) construction of rhynchodeum wall, mouth, and esophagus (g) rhynchodeal sphincter, mouth, and esophagus, (h) rhynchodeum and esophagus in anterior end of brain. Scale $100 \mu \mathrm{m}(\mathrm{a}-\mathrm{h})$. br $=$ brain; ce = cephalic glands; $\mathrm{cg}=$ cerebral sensory organ; $\mathrm{cm}=$ circular muscle layer of body wall; $\mathrm{cs}=$ circular muscle layer of proboscis sheath; $\mathrm{dp}=$ dermis of proboscis; $\mathrm{dr}$ = dermis; es = esophagus; ip = inner longitudinal muscle layer of proboscis; li = layer of inner longitudinal muscles; $1 \mathrm{~m}=$ longitudinal muscle layer of body wall; $1 \mathrm{~s}$ $=$ longitudinal muscle layer of proboscis sheath; $\mathrm{md}=$ middorsal nerve; $\mathrm{mo}=$ mouth; ot $=$ outer epithelium of proboscis; ou = outer circular muscle layer of proboscis; $\mathrm{pn}=$ proboscis nerve; $\mathrm{pp}=$ proboscis pore; $\mathrm{rc}$ = rhynchocoel; rd = rhynchodeum; $r$ s = rhynchodeal sphincter; we = foregut wall. 

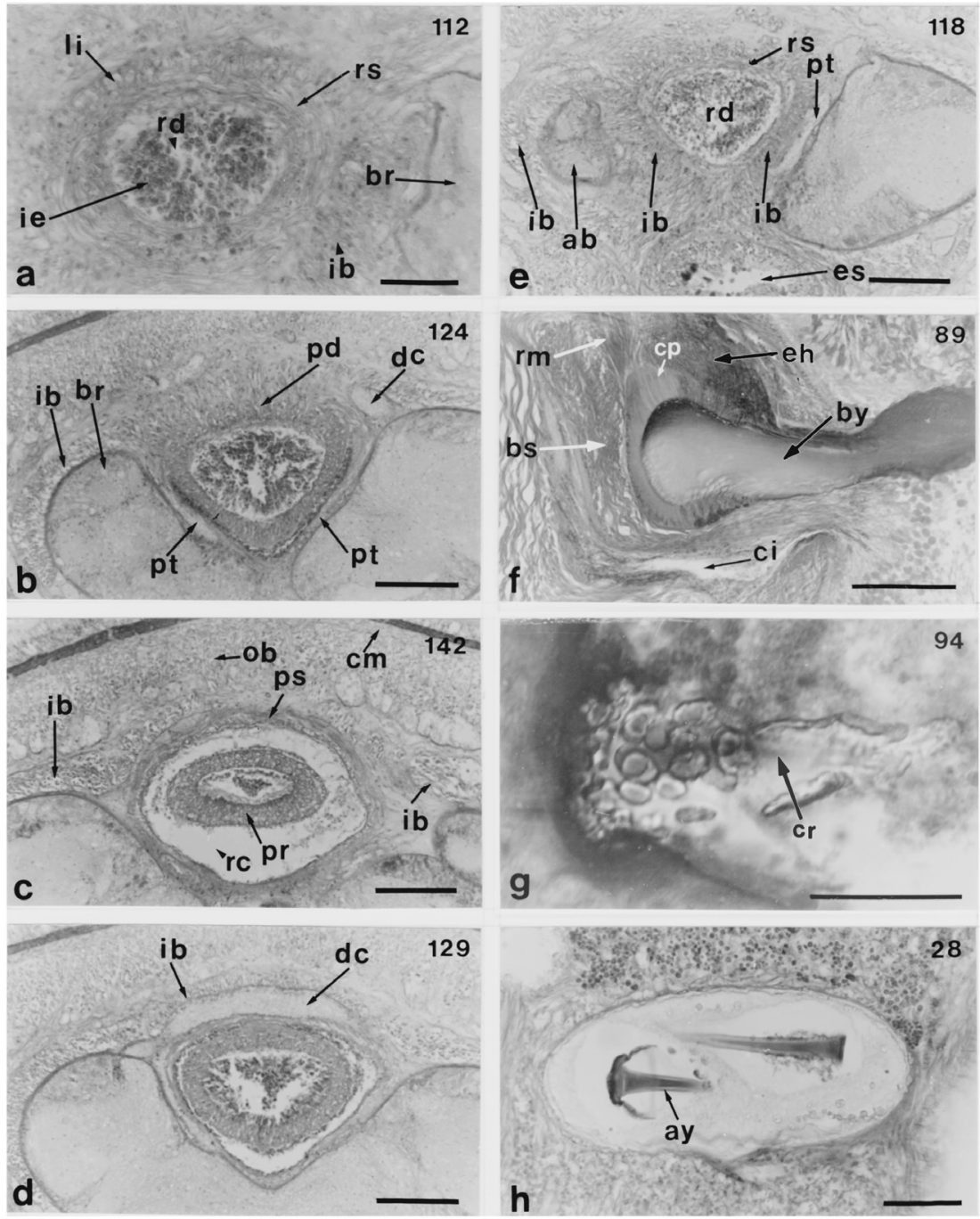

Fig. 3. Amphiporus formidabilis. Transverse sections between 112-142 from anterior end of body (a-e) and frontal sections between 28-94 of proboscis apparatus (f-h), showing (a) construction of rhynchodeum, (b) proboscis insertion on the dorsal side of the rhynchodeum, (c) division of longitudinal muscle layer of body wall into the inner and outer layers, (d) closed cylinder of inner layer of longitudinal muscle covering the brain, (e) inner layer of longitudinal muscle on the anterior end of the brain (left side) and proboscis nerve trunk (right side), (f) basis of central stylet, (g) central stylet, (h) accessory stylet pouch. Scale $50 \mu$ $\mathrm{m}(\mathrm{a}, \mathrm{g}, \mathrm{h})$, and $100 \mu \mathrm{m}$ (b-f). ab = anterior end of brain; ay = accessory stylet;br = brain; bs = bolster; by $=$ basis of central stylet; $\mathrm{ci}=$ cavity of proboscis diaphragm; $\mathrm{cm}=$ circular muscle layer of body wall; $\mathrm{cp}=$ cap-like tissue; $\mathrm{cr}=$ central stylet; $\mathrm{dc}=$ dorsal commissure of brain; $\mathrm{eh}=$ eosinophilic glands; es = esophagus; ib = inner longitudinal muscle of body wall; ie = inner epithelium of rhynchodeum; $1 \mathrm{i}=$ layer of inner longitudinal muscles; ob = outer longitudinal muscle of body wall; $\mathrm{pd}=$ proboscis insertion on the dorsal side of the rhynchodeum; $\mathrm{pr}=$ proboscis; $\mathrm{ps}=$ proboscis sheath; $\mathrm{pt}=$ proboscis nerve trunk; $\mathrm{rc}=$ rhynchocoel; $\mathrm{rd}=$ rhynchodeum; $\mathrm{rm}=$ retracter muscle of the basis of central stylet; $\mathrm{rs}$ = rhynchodeal sphincter. 
eosinophilous, cap-like outer layer of tissue, $30 \mu \mathrm{m}$ thick (Figs. 3f, 4a, b). The bolster, composed of circular muscles ( $80 \mu \mathrm{m}$ thick), lies under the basis and its muscles extend upward along the cavity of the diaphragm (Figs. 3f, 4a, b). A glandular substance was extruded from eosinophilous glands on the lateral sides of the basis (Figs. 3f, 4a, b). The proboscis diaphragm consists of an outer layer of longitudinal muscles and three layers arranged at right angles to the basis: an eosinophilous outer epithelium, a glandular layer on the lateral sides of the basis, and a bundle of retractor muscles (Figs. 3f, $4 a, b)$.

The stylet bulb consists of a muscular ball $(0.6 \mathrm{~mm}$ in diameter by $0.8 \mathrm{~mm}$ in height $)$ and has a slender canal continuous with the cavity of the proboscis diaphragm (Fig, 4a). The cavity extending laterally to the portion below the bolster has a mass of glandular cells (Fig. 4a). It opens into a large sac-like cavity with a longitudinal muscle layer (Fig. 4a, c).

The proboscis wall in the anterior chamber consists of an outer glandular epithelium, dermis, and circular and longitudinal muscle layers. The nerve plexus of proboscis nerves is in the longitudinal muscle layer (Fig. 2a). In the posterior chamber, there is no circular muscle layer (Fig. 4d).

There are six accessory stylet pouches arranged around the central stylet, each containing two stylets. The proboscis has 26 nerves in one specimen and 30 nerves in the other specimen. Griffin (1898) reported eight or 12 pouches in the specimens collected at Puget Sound and Alaska.

\section{Alimentary canal}

The alimentary canal has five major divisions: esophagus, stomach, pylorus, midgut (with anteriorly-directed caecum and lateral diverticula), and hindgut. The esophagus opens into the rhynchodeum (Fig. 2e-h). The distance between the posterior end of the proboscis pore and the mouth is $370 \mu \mathrm{m}$, and that between the mouth and the brain is about $170 \mu \mathrm{m}$; the mouth is thus relatively close to the brain. Neither the esophagus nor the stomach has longitudinal or circular musculature.

The esophagus, compressed between the rhynchodeum and the cephalic glands on the ventral side of the head, is flattened dorsoventrally. It extends far behind the brain; the distance between the mouth and the posterior end of the esophagus is about $0.7 \mathrm{~mm}$. In the cephalic region, the esophagus lies under the rhynchocoel. There is no space between the esophagus and the ventral commissure of the brain (Fig. 4e). The transitional portion of the esophagus leading into the stomach is about $320 \mu \mathrm{m}$ long (Fig. 4f)). Under the ventral commissure the esophagus is $70 \mu \mathrm{m}$ wide, its posterior portion is $300 \mu \mathrm{m}$ wide.

The stomach, $820 \mu \mathrm{m}$ long and about three times as long as the brain, has eight lengthwise folds protruding outward (Fig. 4g). Posteriorly, the folds become shorter as the stomach changes gradually into the pylorus (Fig. 4h).

The pylorus is about $3.7 \mathrm{~mm}$ long and about 4.5 times as long as the stomach. It is wide and flattened dorsoventrally, being $580 \mu \mathrm{m}$ wide at its junction with the stomach (Fig. 4h). Just before opening into the midgut, its width narrows to $70 \mu \mathrm{m}$ (Fig. 5a).

The intestinal caecum has a pair of anterior tubular diverticula $2.6 \mathrm{~mm}$ long, and its anterior end extends to the posterior end of the brain. The caecum has 15 pairs of lateral diverticula; these do not branch laterally (Fig. 5b). The intestine also has lateral diverticula that do not branch laterally.

The rectum, $60 \mu \mathrm{m}$ long, lacks circular muscles (Fig. 5c). The anus, $40 \mu \mathrm{m}$ long, opens on the ventral side of the body (Fig. 5d). The tail behind the anus $(50 \mu \mathrm{m})$ is divided into two portions (Fig. $5 d)$.

\section{Blood-vascular system}

The blood vascular system has three longitudinal vessels. The two cephalic blood vessels lateral to the rhynchodeum anastomose just behind the proboscis pore near the tip of the head to form the cephalic loop, $110 \mu \mathrm{m}$ wide, $20 \mu \mathrm{m}$ high, and $20 \mu \mathrm{m}$ long (Fig. 5e). Farther posteriorly, however, the cephalic vessels do not give off cerebral vessels; they turn medially in front of the brain and enter 

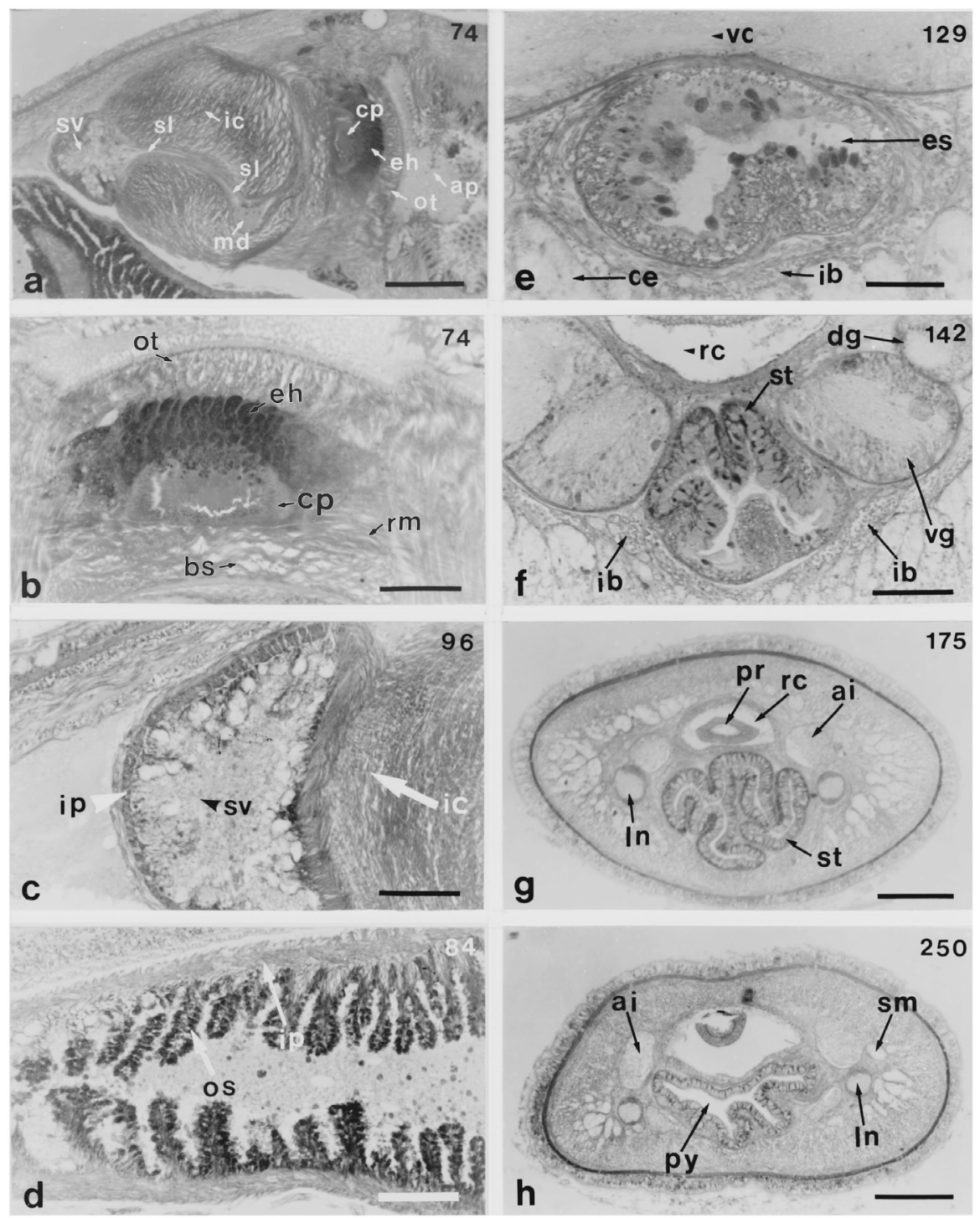

Fig. 4. Amphiporus formidabilis. Frontal sections between 74-96 of proboscis apparatus (a-d) and transverse sections between 129-250 from anterior end of body (e-h), showing (a) proboscis diaphragm and stylet bulb of proboscis, (b) wall of proboscis diaphragm, (c) sac-like cavity of stylet bulb, (d) posterior chamber of proboscis, (e) esophagus under the ventral commissure of the brain, (f) transitional portion of esophagus into stomach, (g) stomach with six folds bending outside, (h) anterior portion of pylorus. Scale $50 \mu \mathrm{m}(\mathrm{e})$ and $100 \mu \mathrm{m}(\mathrm{a}-\mathrm{d}, \mathrm{f}-\mathrm{h}) . \mathrm{ai}=$ anterior tubular diverticulum of intestinal caecum; ap = anterior chamber of proboscis; bs = bolster; ce = cephalic glands; $\mathrm{cp}=$ cap-like tissue; $\mathrm{dg}=$ dorsal ganglion; $\mathrm{eh}=$ eosinophilic glands; es = esophagus; $\mathrm{ib}=$ inner longitudinal muscle of body wall; ic = interlacing circular muscles of stylet bulb; ip = inner longitudinal muscle layer of proboscis; $l n=$ lateral nerve; $m d=$ mass of glandular cells; os = outer epithelium of proboscis; ot = outer epithelium of proboscis; $p r$ = proboscis; $p y=$ pylorus; $\mathrm{rc}=$ rhynchocoel; $\mathrm{rm}=$ retractor muscle of the basis of the central stylet; $\mathrm{sl}=$ slender canal of stylet bulb; $\mathrm{sm}=$ subepithelial glands; $\mathrm{st}=$ stomach; $\mathrm{sv}=$ sac-like large cavity; $\mathrm{vc}=$ ventral commissure of brain; $\mathrm{vg}$ $=$ ventral ganglion. 

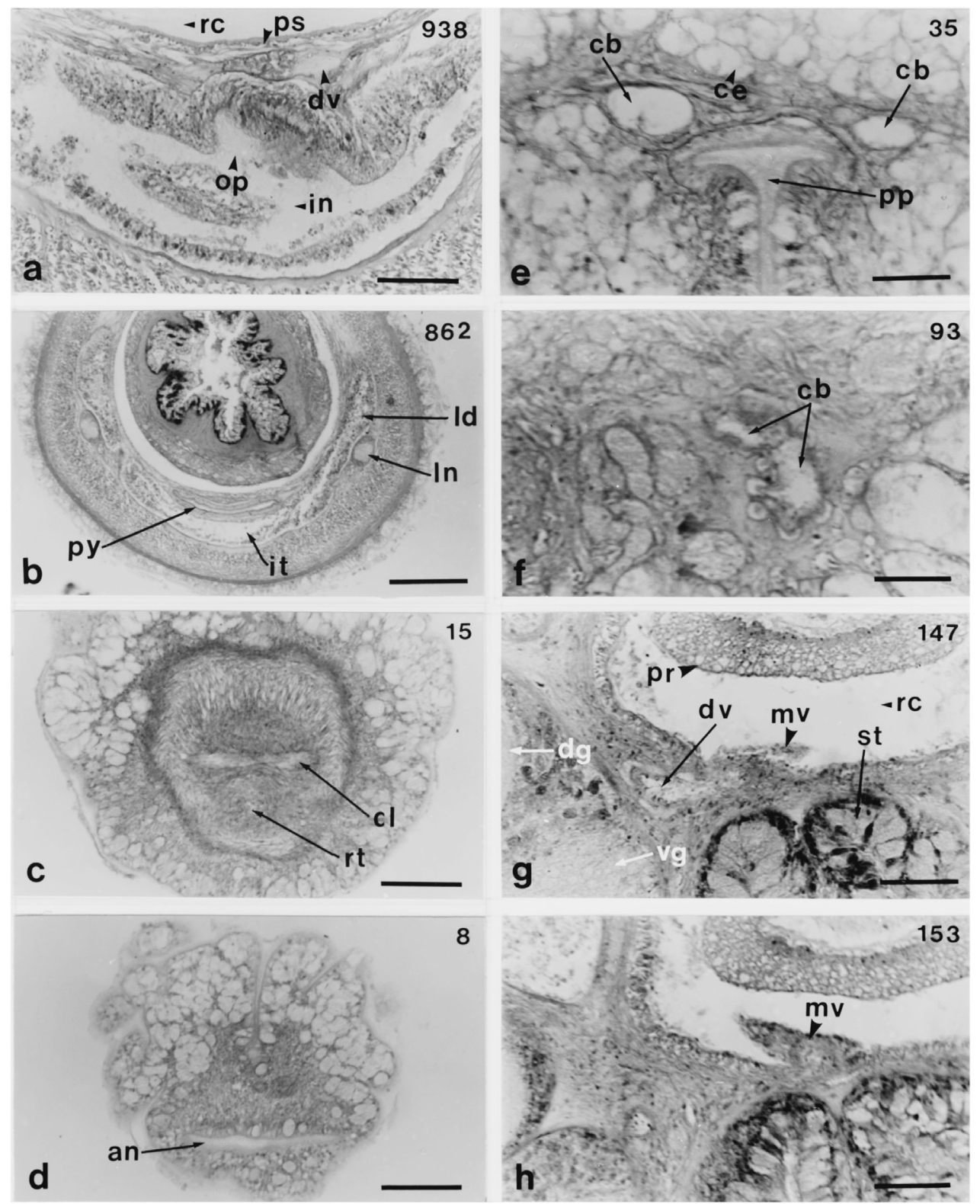

Fig. 5. Amphiporus formidabilis. Transverse sections between $35-938$ from anterior end of body (a, b, e-h) and eight and 15 from posterior end of body (c, d), showing (a) opening of pylorus, (b) lateral diverticulum of intestinal caecum not branching, (c) rectum, (d) anus, (e) cephalic blood vessels and proboscis pore, (f) cephalic vessel (right side) broadened, (g) dorsal vessel entering median vascular plug, (h) median vascular plug of dorsal blood vessel. Scale $50 \mu \mathrm{m}(\mathrm{e}-\mathrm{h})$ and $100 \mu \mathrm{m}(\mathrm{a}-\mathrm{d})$. ai = anterior tubular diverticulum of intestinal caecum; an = anus; $\mathrm{cb}=$ cephalic blood vessel; $\mathrm{ce}=$ cephalic glands; $\mathrm{cl}=$ commissure of lateral nerves; $\mathrm{dg}=$ dorsal ganglion; $\mathrm{dv}=$ dorsal blood vessel; in = intestine; it = intestinal caeum; $1 d$ = lateral diverticulum of intestinal caecum; $l n=$ lateral nerve; $m v=$ median vascular plug; op = opening of pylorus; $\mathrm{pp}=$ proboscis pore; $\mathrm{pr}=$ proboscis; $\mathrm{ps}=$ proboscis sheath; $\mathrm{py}=$ pylorus; $\mathrm{rc}=$ rhynchocoel; rt = rectum; st = stomach; vg = ventral ganglion. 
the brain ring. At the posterior end of the cerebral sensory organs the cephalic vessels become broadened (Fig. 5f). The two cephalic vessels extend alongside the ventrolateral portions of the rhynchocoel; the left one joins the dorsal vessel in the middle of the brain, and then enters the proboscis sheath as a single median vascular plug (Fig. $5 \mathrm{~g}, \mathrm{~h}$ ). This plug, about $110 \mu \mathrm{m}$ long, continues posteriorly under the proboscis sheath between the rhynchocoel and the alimentary canal. The three post-cerebral vessels are not linked transversely by connectives.

Behind the brain, the lateral vessels enter the nephridial region, which extends from the level of the posterior end of the brain to that of the pylorus. There are no transverse anastomoses of the lateral vessels in the intestinal region.

Near the posterior end of the body, a short distance $(60 \mu \mathrm{m})$ anterior to the commissure of the lateral nerves, the blood vessels unite to form a single slender vessel (Fig. 6a). This anastomosis is $510 \mu \mathrm{m}$ posterior to the end of the rhynchocoel and the proboscis sheath.

\section{Nervous system}

The cerebral ganglia in transverse section, arranged to form a V-shaped angle of about $120^{\circ} \mathrm{C}$ (Fig. $6 \mathrm{~b})$ and covered with thin fibrous connective tissue, are large $(280 \mu \mathrm{m})$ and have neither neurochord cells nor an inner neurilemma. Behind the ventral commissure of the brain, the fiber cores are not divided into the dorsal and ventral cores for as much as $70 \mu \mathrm{m}$ (Fig. 6c). The dorsal ganglia do not branch posteriorly into dorsal and ventral lobes (Fig. 6d). The ventral ganglia form the lateral nerve cords behind the posterior ends of the dorsal ganglia.

The right and left ganglia are connected by a short dorsal commissure, $60 \mu \mathrm{m}$ thick, and by a longer ventral commissure, $110 \mu \mathrm{m}$ thick; these commissures are located about the same transverse level (Figs. 3d, 6b).

In the pyloric region, the lateral nerve cords, ventrolateral in position, lie in the parenchyma inside the longitudinal musculature of the body wall (Fig. 5b). They give off dorsal or ventral peripheral nerves (Fig. 6e); the first of these is at the transverse level of the middle of the stomach.

Several slender but conspicuous nerves originate from the brain. They branch out pre-and postcerebrally to supply various structures. A proboscis nerve trunk arises from the latero-ventral surface of the brain, $60 \mu \mathrm{m}$ anterior to the root of the ventral commissure, and extends dorsally and posteriorly into the rhynchodeum wall, where the proboscis is inserted (Figs. 3b, e, 6f). Both trunks of the proboscis nerves branch posteriorly into 26 nerves that lie in the proboscis. A small nerve, $220 \mu$ $\mathrm{m}$ long, extends from the lateral side of each dorsal ganglion to the posterior end of each cerebral sensory organ (Fig. 7f). Rhynchodeal and foregut nerves were not observed. A thick transverse nerve on the ventral side of the stomach is located at the level of the posterior end of each dorsal ganglion (Fig. 6g). The mid-dorsal nerve lies between the dermis and the circular muscle layer of the body wall (Fig. 2a). It does not extend anteriorly beyond the brain. The anterior end of the brain gives rise to three nerve cords that enter various structures of the head (Fig. 6h).

The lateral nerve cords have a fibrous core without myofibrillae or accessory nerves. The commissure of the lateral nerve cords is on the dorsal side of the rectum (Fig. 5c).

\section{Sensory organs}

The eyes are distributed in four groups confined to an area $820 \mu \mathrm{m}$ long between the anterior end of the proboscis pore and the brain. The two anterior groups on the right and left side of the head have 32 and 23 eyes, respectively; there are 22 and 21 eyes in posterior group. The eyes of the anterior groups are distributed over a length of $370 \mu \mathrm{m}$ (right side) and $500 \mu \mathrm{m}$ (left side), and those of the posterior groups over a length of $370 \mu \mathrm{m}$ (right side) and $340 \mu \mathrm{m}$ (left side). The eyes are of the inverted pigment-cup type and are up to $75 \mu \mathrm{m}$ wide and $110 \mu \mathrm{m}$ high. There is no large nucleus in the center of the eye (Fig. 7a).

The frontal glands, above the cephalic furrow of the head and the proboscis pore, extend posteriorly for a distance of $190 \mu \mathrm{m}$ (Fig. 7b); the posterior end of the mass is separated by a distance 

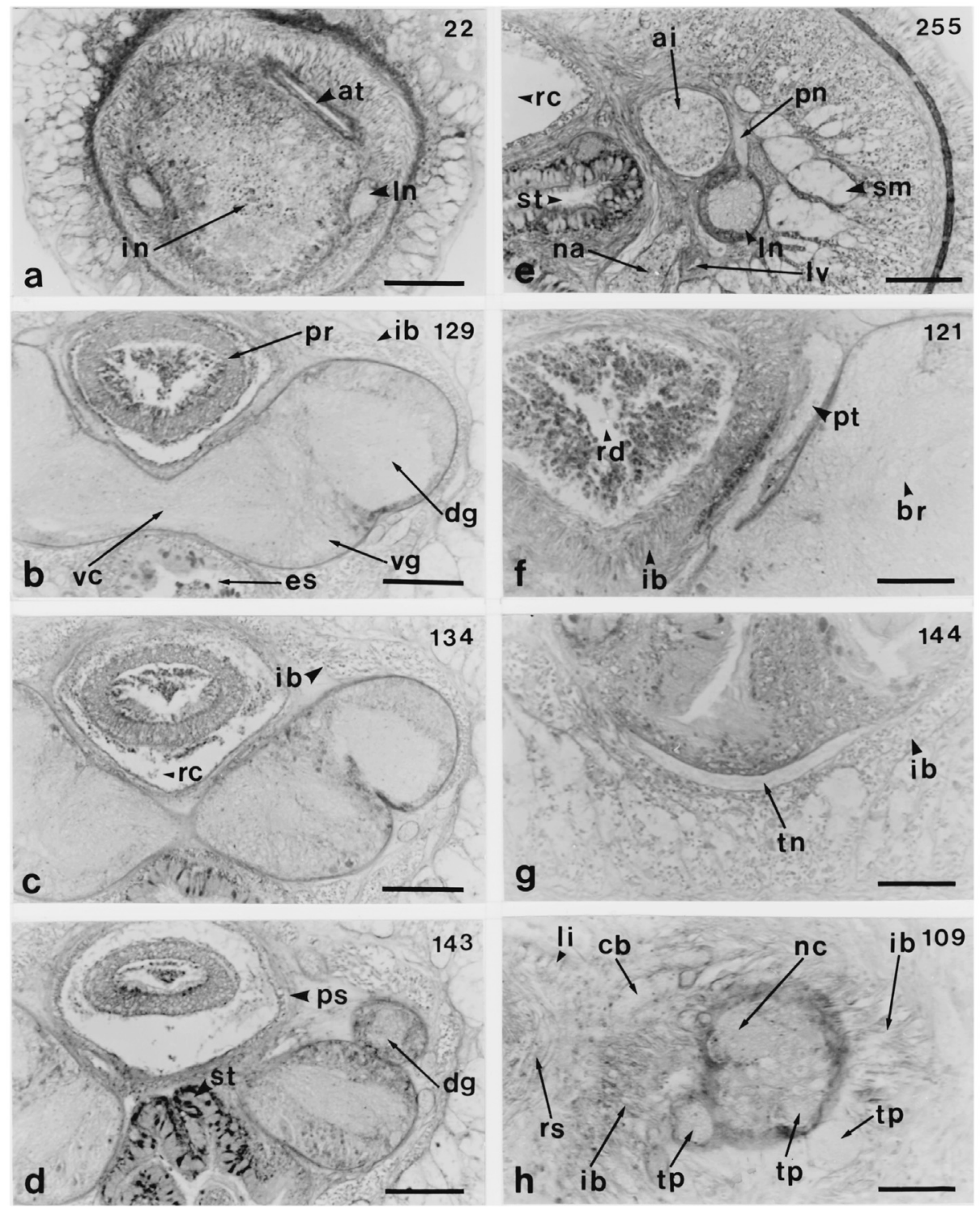

Fig. 6. Amphiporus formidabilis. Transverse sections from posterior end of body (a) and between 109-255 from anterior end of body (b-h), showing (a) transverse anastomosis of dorsal and lateral blood vessels, (b) Vshaped brain, (c) separation of dorsal and ventral ganglion, (d) dorsal ganglion not branching into dorsal and ventral lobes, (e) peripheral nerve, (f) proboscis nerve trunk, $(\mathrm{g})$ transverse nerve running under the stomach, (h) nerve cords from anterior end of brain. Scale $50 \mu \mathrm{m}$ (f-h) and $100 \mu \mathrm{m}$ (a-e). ai = anterior tubular diverticulum of intestinal caecum; at = anastomosis of lateral and dorsal blood vessels; br $=$ brain; $\mathrm{cb}=$ cephalic blood vessel; $\mathrm{dg}=$ dorsal ganglion; es = esophagus; $\mathrm{ib}=$ inner longitudinal muscle of body wall; in = intestine; $\mathrm{li}=$ layer of inner longitudinal muscles; $\mathrm{ln}=$ lateral nerve; $\mathrm{lv}=$ lateral blood vessel; na $=$ nephridia $; \mathrm{nc}=$ nerve cords from anterior end of brain; $\mathrm{pn}=$ peripheral nerve; $\mathrm{pr}=$ proboscis; $\mathrm{ps}=$ proboscis sheath; $\mathrm{pt}=$ proboscis nerve trunk; $\mathrm{rc}=$ rhynchocoel; $\mathrm{rd}=$ rhynchodeum; $\mathrm{sm}=$ subepithelial glands; st = stomach; $t \mathrm{t}=$ transverse nerve running under stomach; $\mathrm{tp}=$ thick nerve from dorsal ganglion; $\mathrm{vc}=$ ventral commissure of brain; $\mathrm{vg}=$ ventral ganglion. 

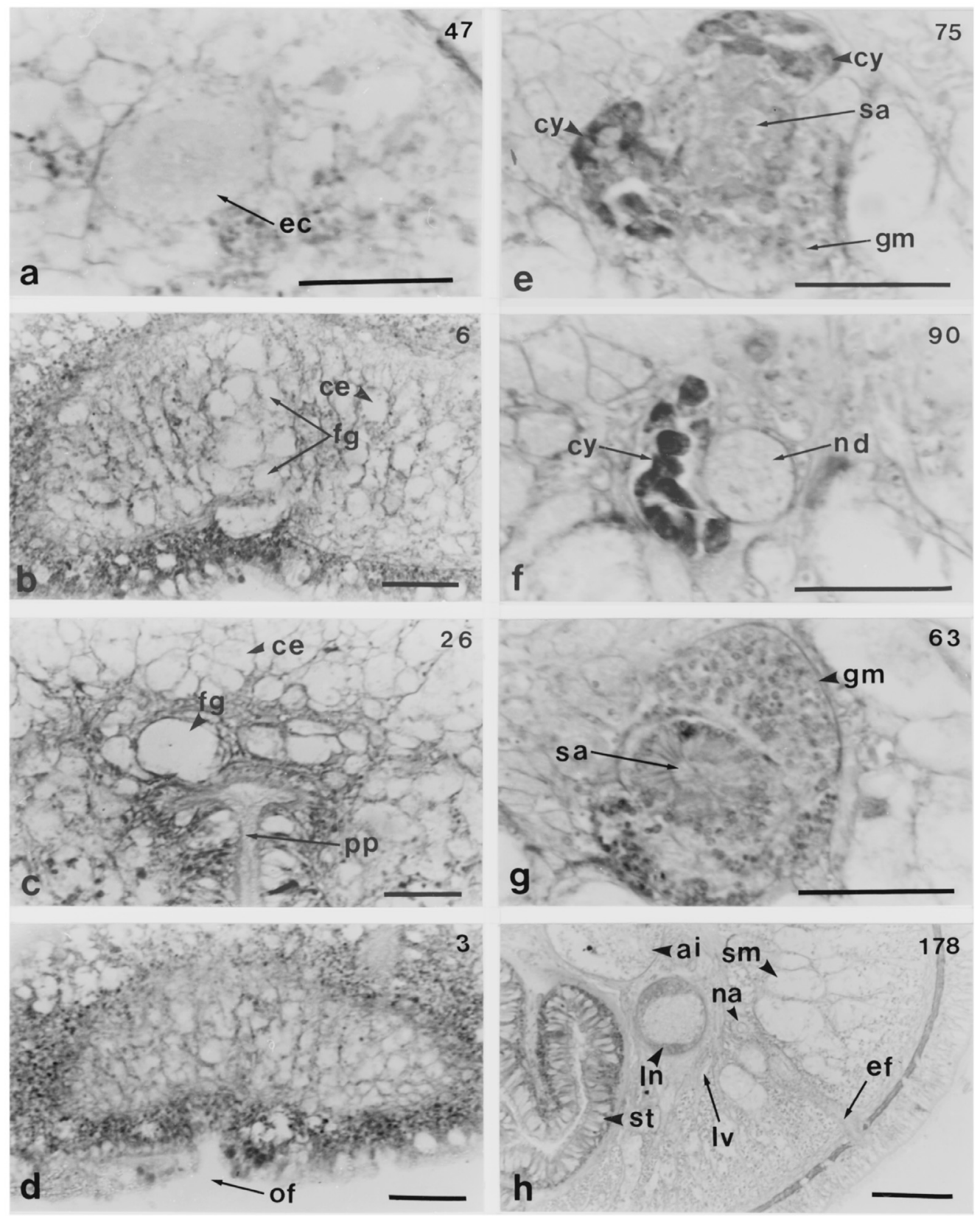

Fig. 7. Amphiporus formidabilis. Transverse sections between 3-178 from anterior end of body (a-h), showing (a) eye; (b) frontal glands, (c) proboscis pore and frontal glands, (d) opening of frontal organ, (e) cerebral sensory organ, (f) nerve from dorsal ganglion and cyanophilic glands of cerebral sensory organ, $(\mathrm{g})$ sensory cannal, (h) efferent duct. Scale $50 \mu \mathrm{m}(\mathrm{a}-\mathrm{h})$. ai = anterior tubular diverticulum of intestinal caecum; ce = cephalic glands; $c y=$ cyanophilic glandular mass; ec =eye; ef $=$ efferent duct; fg $=$ frontal glands; gm = ganglionic mass; $1 \mathrm{n}=$ lateral nerve; lv = lateral blood vessel; na = nephridia; nd = nerve running between dorsal ganglion and cerebral sensory organ; of = opening of frontal organ; $\mathrm{pp}=$ proboscis pore; $\mathrm{sa}=$ sensory canal; $\mathrm{sm}=$ subepithelial glands; $\mathrm{st}=$ stomach . 
of about $140 \mu \mathrm{m}$ from the opening of the cerebral sensory organs. In the posterior region of the frontal organ, a small mass of glands is located above the proboscis pore (Fig. 7c). The opening of the frontal organ is situated at the ventral side of the anterior tip of the head (Fig. 7d).

The cephalic glands occupy an area $1.2 \mathrm{~mm}$ long between the anterior tip of the head and the middle of the stomach; they are especially well developed around the proboscis pore and on the ventral side of the head, but are lacking on the dorsal side of the brain.

Subepithelial glands, on the lateral sides of the body, extend from the level of the middle of the stomach to the posterior portion of the pylorus.

The small cerebral sensory organs, $250 \mu \mathrm{m}$ long, are covered with fibrous connective tissue and there is a distance of $140 \mu \mathrm{m}$ between their posterior ends and the anterior end of the brain. They are nearly circular in transverse section $(160 \mu \mathrm{m}$ in diameter in their middle portions) and consist of a central sensory canal, a ganglionic mass situated lateroventrally, and two cyanophilic glandular masses situated on both the dorsal and ventral side (Fig. 7e). A slender nerve runs from each dorsal ganglion to the posterior end of each cerebral sensory organ (Fig. 7f).

The cerebral organ canal, ciliated and $120 \mu \mathrm{m}$ long, begins on the ventral side of the head about $360 \mu \mathrm{m}$ from the anterior tip of the head or about $120 \mu \mathrm{m}$ posterior from the proboscis pore. It runs obliquely to the cerebral sensory organ. The epithelium of the canal is $20 \mu \mathrm{m}$ thick. Before it enters the cerebral organ, it does not widen, and does not have a U-shaped ciliated sensory portion. The sensory canal that follows the organ canal is surrounded by a mass of ganglionic cells (Fig. 7g). When the sensory canal moves to the dorsal side of the cerebral organ, the ganglionic mass becomes located on its ventral side (Fig. 7e).

Excretory and reproductive system

The excretory system is not well developed in the foregut region; it extends to the level of the posterior end of the pylorus. Excretory tubules wind around and along the lateral blood vessels. The efferent ducts are short but conspicuous and numerous (18 on the right and 9 on the left), reaching the excretory pore on the latero-ventral side of the body (Fig. 7h). The first pore is ventral to the lateral nerve cord, while the others are dorsal to it.

Sexes are separate. Immature oogonia and immature spermatogonia are scattered between the body wall and the intestine.

Systematic discussion

Eight specimens collected at San Juan Island in 1964 were identified into Amphiporus formidabilis Griffin, 1898, described on the basis of material collected at Puget Sound and Alaska in 1897 and 1898. For identification, Griffin cited 13 characters of the body, as follows: 1$)$ eyes (100$150 \pm$ ) numerous; 2) eyes arranged in two groups; 3 ) mouth opening into rhynchodeum; 4) intestinal caeca extending to brain; 5) rhynchocoel extending to end of body; 6) central stylet shorter than basis; 7) cephalic commissure just behind proboscis pore; 8) cephalic glands dense; 9) subepithelial glands abundant in anterior portion of body; 10) cerebral sensory organ in front of brain; 11) efferent ducts numerous, some opening dorsally, others laterally; 12) accessory stylet pouches $8 \pm$ or $12 \pm$ with 2 stylets (Table 2). Griffin did not record the number of proboscis nerves (13) or deal with the precerebral septum (14).

The characters of the body cited by Griffin (1-12) were similar to those of A. formidabilis in the present study, except for the presence of six accessory stylet pouches (Table 2, Character 12). Coe (1905), however, showed the number of accessory stylets was 6-8-12 with one or two stylets.

The genus Amphiporus is one of the early established genera, and about 120 species have been described (Gibson and Crandall, 1989). What had been considered to be the type species, Amphiporus albicans Ehrenberg, 1831, was not adequately described, and the diagnosis for the genus Amphiporus was not established until recently (Gibson, 1985; Norenburg, 1986). Gibson and Crandall (1991) 
Table 2. Summary of 14 morphological characters which can be used to distinguish between six species of the genus Amphiporus. Data taken from Griffin,1898, Coe, 1901, 1905, Berg, 1972, Iwata, 1952 and the present study.

\begin{tabular}{|c|c|c|c|c|c|c|c|c|c|c|c|c|c|c|}
\hline \multicolumn{15}{|c|}{ Character } \\
\hline & 1 & 2 & 3 & 4 & 5 & 6 & 7 & 8 & 9 & 10 & 11 & 12 & 13 & 14 \\
\hline A. formidabilis in Griffin, (1898) & + & + & + & + & + & + & + & + & + & + & + & $+\mathrm{a}$ & 0 & 0 \\
\hline A. formidabilis (Iwata, 2007) & + & + & + & + & + & + & + & + & + & + & + & $+\mathrm{c}$ & $+\mathrm{c}$ & - \\
\hline A. lactifloreus (Berg, 1972) & $+\mathrm{a}$ & + & + & - & + & + & 0 & + & - & + & $+\mathrm{a}$ & $+\mathrm{e}$ & $+\mathrm{d}$ & + \\
\hline A. exilis (Coe, 1901) & + & + & 0 & + & + & + & 0 & + & + & + & + & $+\mathrm{b}$ & 0 & 0 \\
\hline A. formidabilis (Coe, 1905) & + & + & 0 & + & + & + & + & + & + & + & + & $+\mathrm{b}$ & $+\mathrm{a}$ & 0 \\
\hline A. formidabilis (Iwata, 1952) & + & + & + & + & + & + & + & + & + & + & + & $+\mathrm{d}$ & $+\mathrm{b}$ & - \\
\hline
\end{tabular}

1: Eyes numerous, about 100-150 (+); eyes few, about 10-13 (+a)

2: Eyes arranged in two groups $(+)$.

3: Mouth opening into rhynchodeum $(+)$ or no record $(0)$.

4: Intestinal caeca extending to brain $(+)$ or not reaching brain (-).

5: Rhynchcoel extending to end of body $(+)$.

6: Central stylet shorter than basis and stylet pouches around central stylet $(+)$

7: Cephalic commissure just behind proboscis pore $(+)$ or no record $(0)$.

8: Cephalic glands dense $(+)$

9: Subepithelial glands abundant in anterior portion of body (+) or absent (-).

10: cerebral sensory organ in front of brain $(+)$.

11: Efferent ducts numerous, some opening dorsally, others laterally $(+)$ or efferent ducts only $2(+a)$.

12: Accessory stylet pouches (+a) $8 \pm$ or $12 \pm$ with 2 stylets, $(+b) 6-8-12$ with 1 or 2 stylets, $(+c) 6$ with 2 stylets, (+d) 6 with 1,2 or 3 stylets, +e 2 .

13: Number of proboscis nerves; (+a) 30, (+b) 18, (+c) 26 or 30 or $(+d) 14$, or (0) no record.

14: Precerebral septum present $(+)$, absent $(-)$ or no record $(O)$

proposed to the International Committee of the Zoological Nomenclature that Planaria lactifloreus Johnston, 1828, redescribed as an Amphiporus by Berg (1972), become the type species. This was accepted by the committee and published as opinion 1675 .

Amphiporus lactifloreus and Amphiporus formidabilis of the present study are similar with respect to six characters $(2,3,5,6,8$, and 10$)$; they are different with respect to seven characters $(1,4$, $9,11,12,13$, and 14) (Table 2).

Molecular systematic analysis has revealed that A. formidabilis and A. lactifloreus belong to a monophyletic group (Tholleson and Norenburg, 2003). This group contains not only the genus Amphiporus, but also species of the genus Paranemertes, which are placed in the family Emplectonematidae. So Amphiporidae and Amphiporus are not monophyletic. Diagnosis of the Amphiporidae and Amphiporus should be therefore made in a later study. For this reason, the present study did not change the diagnosis at the generic level (Gibson 1982a, 1982b), and the placement of $A$. formidabilis in the genus Amphiporus seems to be appropriate.

Coe (1901) described Amphiporus exilis collected at the stations from Victoria, B. C. to Dutch Harbor, Unalaska. Later he synonymized it with A. formidabilis Griffin, 1898 (Coe, 1904), and described it again (Coe, 1905). The characters of the body in this species were similar to those of $A$. formidabilis collected at San Juan Island (Table 2).

In A. exilis, however, Coe (1901) wrote that the anterior pouches of the intestinal caecum reach forward on each side; even at the anterior and posterior levels of the brain there are several rather slender lobes on each side. These lobes lie mainly above the lateral nerves, but send off branches below the nerves at frequent intervals. Somewhat farther back in the esophageal region, the lateral 
lobes join the main unpaired caecum. The arrangement of the lateral lobes and intestinal caecum posterior to the brain seems to be unique in A. exilis.

The specimens from Kyusyu (Iwata, 1952) and from San Juan Island in the present study were similar in body characteristics except for the number of proboscis nerves (18 in the former, 26 or 30 in the latter).

Thollesson and Norenburg (2003) accepted Amphiporus formidabilis Griffin, 1898 as a member of the family Amphiporidae.

\section{Amphiporus imparispinosus Griffin, 1898}

(Pl. 1, fig. 2; Figs. 1b-e; Figs. 8-12; Table 3)

Amphiporus imparispinosus Griffin, 1898: p. 210, figs. 19-20; Coe, 1905: p. 247-249, pl. 16, figs. 99, 100, pl. 25, figs. 195-197, text-fig. 53; Correa, 1964: p. 542-544; Gibson, 1995: p. 285; Yamaoka, 2005 : p.145-147.

Amphiporus leuciodus Coe, 1901: p. 51-53, pl. 7, fig. 6, text-fig. 13; Punnett, 1901: p. 95; Gibson, 1995: p. 287.

Amphiporus similis Coe, 1905: p. 249, 250, pl. 16, figs. 93, 94, pl. 22, figs. 152, 153; Gibson, 1995: p. 294.

Specific diagnosis

Light brown or pale reddish-yellow, without pattern; with two transverse cephalic furrows; small number of eyes (31) arranged in four groups; three accessory stylet pouches; proboscis with 12 nerves; central stylet-basis with bolster composed of circular muscles; intestinal caecum with a pair of anterior tubular diverticula and 15 pairs of lateral diverticula; lateral nerves have accessory lateral nerve cords; frontal and cephalic glands present, but subepithelial glands absent.

\section{Material}

23 specimens are deposited at the National Museum of Natural History, Smithsonian Institution, Washington, DC, USA.

One specimen (female) collected at Rock point, Lopez Island consisting of 31 slides of stained serial sections of the body, including 22 slides of the head region, five slides of the posterior portion of the body, and four slides of the proboscis. The rest of the body, a long piece of the body and a small piece of the proboscis, were not sectioned.

One specimen (female) collected at San Juan Island consisting of 13 slides of stained serial section of the head region. The rest of the body, a long piece, was not sectioned.

Locality

22 specimens and one specimen, (Pl. 1, fig. 2; Fig. 1e), collected at low tide on the shore between Deadman Bay and Pile Point, San Juan Island on September 3, 1964. One specimen (Fig. 1b) taken by dredging in San Juan Channel (Lat. $48^{\circ} 34.3^{\prime} \mathrm{N}, 123^{\circ} 1.7^{\prime} \mathrm{W}$ ) at a depth of 42 fathoms on October 21 , 1964, and another (Fig. 1c, d) by dredging at Rock Point, Lopez Island (Lat. $48^{\circ} 30^{\prime}$ N, Long. $122^{\circ} 57^{\prime}$ W) on August 17, 1964.

External features

The specimen collected at Rock Point was about $3 \mathrm{~cm}$ long by $0.5 \mathrm{~mm}$ wide (Fig. 1c, d). Its color was light brown or pale reddish-yellow. There were about 10 eyes in each of the two anterior and posterior clusters (Fig. 1c). The anterior cephalic furrows, on the dorsal surface, extended for a short distance toward the midline (Fig. 1c), but on the ventral surface both ran forward anteromedially and met on the midline (Fig. 1d); the more posterior furrow was interrupted on the ventral surface. One specimen collected at San Juan Island was about $14 \mathrm{~cm}$ long by $0.5 \mathrm{~mm}$ wide (Pl. 1, fig. 2); its head 
Table 3. The eyes on 13 specimens of Amphiporus imparispinosus collected at San Juan Island.

\begin{tabular}{ccccc}
\hline \multicolumn{4}{l}{ Anterior group } & \multicolumn{3}{l}{ Posterior group } \\
\hline Left & Right & Left & Right & Total \\
\hline 7 & 7 & 12 & 11 & 37 \\
8 & 7 & 7 & 7 & 29 \\
8 & 8 & 8 & 9 & 33 \\
8 & 8 & 9 & 8 & 33 \\
9 & 9 & 8 & 8 & 34 \\
9 & 9 & 11 & 13 & 42 \\
10 & 7 & 8 & 9 & 34 \\
10 & 9 & 11 & 11 & 41 \\
11 & 12 & 13 & 12 & 48 \\
11 & 10 & 15 & 15 & 51 \\
11 & 8 & 9 & 9 & 37 \\
13 & 9 & 10 & 12 & 44 \\
15 & 15 & 20 & 19 & 69 \\
\hline
\end{tabular}

region is shown in Fig. 1e. It was slender and pale orange, pale flesh color, whitish orange, and white with brown blotches on the dorsal surface. In this specimen, anterior furrows on the dorsal surface were not observed. One specimen collected in San Juan Channel was $3.5 \mathrm{~cm}$ long by $0.8 \mathrm{~mm}$ wide and mostly whitish yellow owing to the color of the digestive tract. Its anterior portion was whitish. There were about 17 eyes in both anterior clusters, and 14 in both posterior clusters (Fig. 1b).

The eyes of 13 specimens collected at San Juan Island were recorded in the Table 3, which showed that the average number of eyes was 41 .

Body wall, musculature, and parenchyma

The epidermis is of uniform thickness in both the cephalic region (average $80 \mu \mathrm{m}$ ) and in the middle region (average $70 \mu \mathrm{m}$ ). Large unicellular glands are lacking. Slender columnar glands are thickly scattered in the cephalic region, and are differenciated into an upper vacuolated and lower cytoplasmic portions (Fig. 8a). At the base of the epidermis rectangular cells (5 $\mu \mathrm{m}$ high) form a continuous colorless stratum (Fig. 8a, b). Large glands are not present in the middle portion of the body and no small eosinophil glands are found here.

The proboscis pore opens at the ventral side of the anterior end of the body and there is no median ventral groove between the tip of the head and the proboscis pore.

The dermis in the pyloric region of the body is $20 \mu \mathrm{m}$ thick and one-fourth as thick as the epidermis. It has no transverse fibrils, cellular bodies or small nerves. Subepithelial glands such as are found in species of Paranemertes are lacking. The body wall musculature consists of an outer circular layer and an inner longitudinal layer; these layers are, respectively, $12 \mu \mathrm{m}$ and $40 \mu \mathrm{m}$ thick in the portion near the posterior end of the brain. The circular muscle layer of the body wall in the cephalic region is divided into two layers; the lower one, $5 \mu \mathrm{m}$ thick, consists of diagonal muscle fibers (Fig. 8a, b, g). 

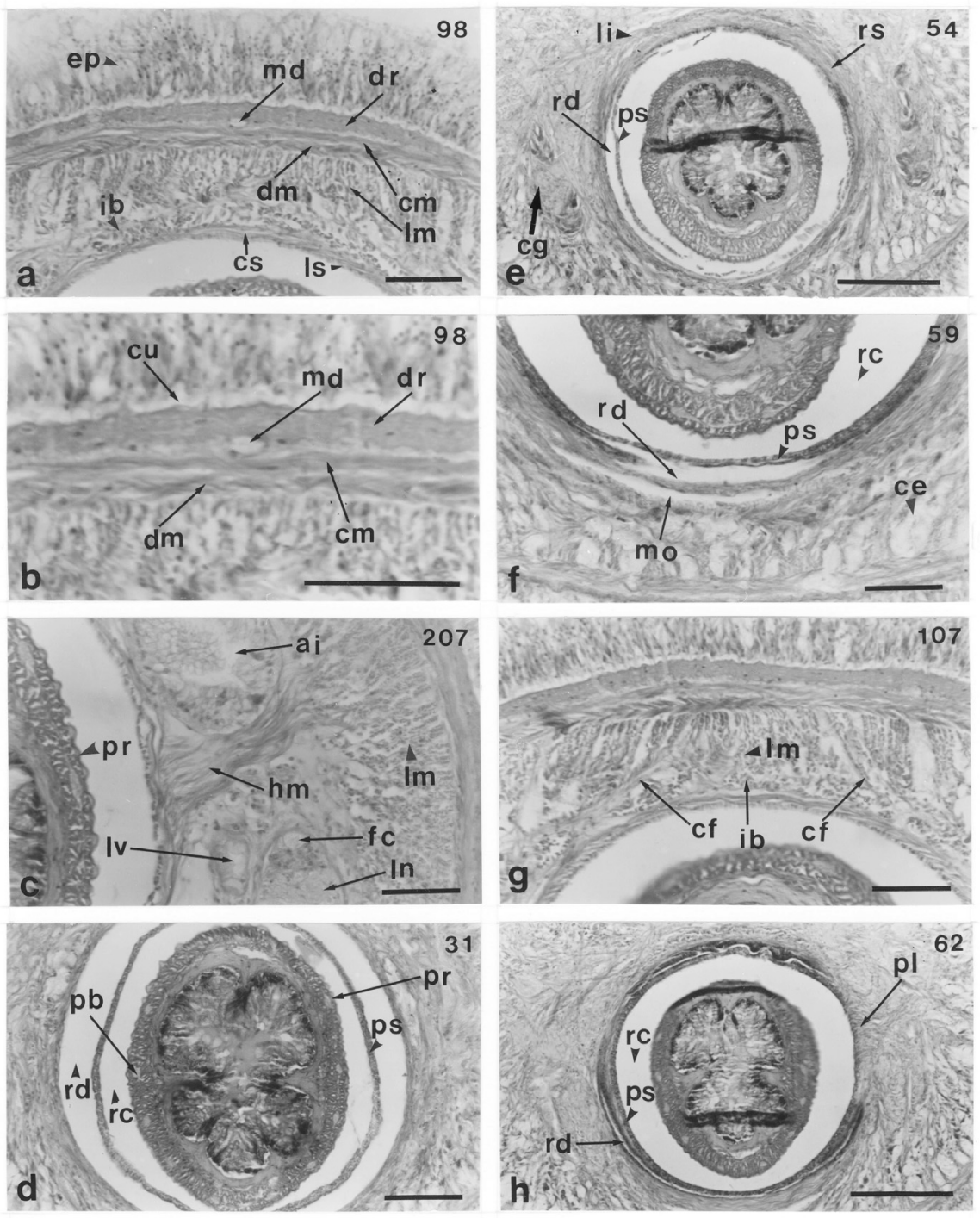

Fig. 8. Amphiporus imparispinosus. Transverse section between 31-207 from anterior end of body (a-h), showing (a) body wall, (b) circular muscle layer of body wall, (c) horizontal muscular bundle, (d) rhynchodeum and rhynchocoel, (e) rhynchodeal sphincter and a thin layer of longitudinal muscle derived from the inner longitudinal muscle layer of the body wall, (f) mouth opening into rhynchodeum, (g) construction of inner and outer longitudinal muscle of body wall, (h) proboscis insertion of rhynchodeum (right side). Scale 50 $\mu \mathrm{m}(\mathrm{a}-\mathrm{d}, \mathrm{f}, \mathrm{g})$ and $100 \mu \mathrm{m}(\mathrm{e}, \mathrm{h})$. ai = anterior tubular branch of intestinal caecum; ce = cephalic glands; cf = circular muscle fibers; $\mathrm{cg}=$ cerebral sensory organ; $\mathrm{cm}=$ circular muscle layer of body wall; $\mathrm{cs}=$ circular muscle layer of proboscis sheath; $\mathrm{cu}=$ colorless stratum; $\mathrm{dm}=$ diagonal muscle layer; $\mathrm{dr}=\mathrm{dermis;}$ ep = epidermis; $\mathrm{fc}=$ fiber core of accessory lateral nerve cord; $\mathrm{hm}=$ horizontal muscular bundle; $\mathrm{ib}=$ inner longitudinal muscle of body wall; $\mathrm{li}=$ layer of inner longitudinal muscles; $1 \mathrm{~m}=$ longitudinal muscle layer of body wall; $1 \mathrm{n}=$ lateral nerve; $1 \mathrm{~s}=$ longitudinal muscle layer of proboscis sheath; $1 \mathrm{v}=$ lateral blood vessel $; \mathrm{md}=$ middorsal nerve $; \mathrm{mo}=$ mouth $; \mathrm{pb}=$ proboscis nerve $; \mathrm{pl}=$ proboscis insertion on lateral side of rhynchodeum; $\mathrm{pr}=$ proboscis; $\mathrm{ps}=$ proboscis sheath; $\mathrm{rc}=$ rhynchocoel; $\mathrm{rd}=$ rhynchodeum; $\mathrm{rs}=$ rhynchodeal sphincter. 
Near the posterior end of the brain, the longitudinal muscle of the body wall becomes divided into inner and outer layers, these separated by parenchyma (Fig. 8a, g). The outer layer continues into the tip of the head without contributing to the proboscis insertion; a pre-cerebral septum is lacking. The inner layer consists of flattened bundles with surrounding membranes; these bundles are arranged outside the proboscis sheath at the dorsal side of the body and the brain, forming a closed cylinder covering the brain and the esophagus (Figs. 8a, g, 9e, 10b, d, g, h, 11a, c, d). In the mid-dorsal portion of the body, at the level where the inner longitudinal muscles of the body wall are separated, there are circular muscle fibers running obliquely from the circular muscle layer of the body wall (Fig. 8g).

In the pyloric region, there are horizontal muscles running between the proboscis sheath or pyloric wall and the longitudinal musculature of the body wall (Fig. 8c). Dorsoventral muscles are lacking. In the intestinal region, above the intestinal diverticula, parenchyma is not well developed between the body wall musculature and the rhynchocoel.

Rhynchodeum, rhynchocoel, and proboscis

Because the proboscis of the specimen had been extruded, the proboscis pore, $70 \mu \mathrm{m} \mathrm{long}, 400$ $\mu \mathrm{m}$ wide, opens mostly on the ventral side of the tip of the head. In transverse section (Fig. 8d), the rhynchodeum, between the end of the proboscis pore and the mouth, is $370 \mu \mathrm{m}$ long and has a tubular lumen $(370 \mu \mathrm{m}$ in diameter). Its wall consists of a thin membranous sheath of tissue $(0.5 \mu \mathrm{m}$ thick $)$ that has no cellular content, cilia, or glands.

The tubular lumen of the rhynchodeum (300 $\mu \mathrm{m}$ in diameter) is columnar and covered by a thin inner epithelium and circular muscles of the rhynchodeal sphincter, which is $20 \mu \mathrm{m}$ thick at the end of the rhynchodeum (Fig. 8e). There is, however, a thin outer layer of longitudinal fibers derived from a layer of the inner longitudinal muscle of the body wall at the posterior end of the cerebral sensory organ (Fig. 8e). The rhynchodeal sphincter decreases anteriorly and disappears at about the end of the first half length of the rhynchodeum. The mouth, on the ventral side of the rhynchodeum, is $370 \mu \mathrm{m}$ from the posterior edge of the proboscis pore (Fig. 8f).

At the proboscis insertion, the rhynchodeum wall, consisting of the inner epithelium and the outer rhynchodeal sphincter, is transformed into the following components of layers of the proboscis apparatus: epithelium, a circular and a longitudinal muscle layer, rhynchocoel, and proboscis sheath, which consists of longitudinal and circular muscle layers (Figs. 8h, 10c, 12f). The distance between the posterior end of the inner longitudinal muscle of the body wall and the portion where the proboscis insertion is located is $370 \mu \mathrm{m}$.

The transformation of the rhynchodeum wall at the proboscis insertion, $60 \mu \mathrm{m}$ long, occurs 100 $\mu \mathrm{m}$ anterior to the dorsal commissure of the brain and $150 \mu \mathrm{m}$ anterior to the anterior end of the brain (Figs. 9a, 11a). The closed cylinder of inner longitudinal muscles before the proboscis insertion sends anteriorly directed muscles into the wall of the rhynchodeum as a thin outer layer for a distance of $60 \mu \mathrm{m}$ long (Fig. 8e). It should be noted, however, that the transformation of the rhynchodeum wall in A. formidbilis occurs just before the dorsal commissure of the brain and the anterior ends of the ganglia.

Head retractor muscles, such as are derived from the outer longitudinal muscle of the body wall, are present, running anteriorly inside the cephalic glands.

The rhynchocoel and the proboscis sheath end a little anterior to the anastomosis of the dorsal and the lateral vessels.

The proboscis diaphragm has a central stylet apparatus consisting of a conical basis about $120 \mu$ $\mathrm{m}$ long. It is about four times as long as a stylet found in an accessory stylet pouch. The basis, $40 \mu \mathrm{m}$ in diameter, has an eosinophilous outer layer $5 \mu \mathrm{m}$ thick (Fig. 9b, c). The ductus ejaculatorius, in contact with the basis, has an epithelium $3 \mu \mathrm{m}$ thick and an outer circular layer $5 \mu \mathrm{m}$ thick. The stylet bulb has a slender central cavity and is enclosed by circular muscle.

The proboscis in the anterior chamber of the proboscis consists of the outer glandular epithelium, dermis, a circular, and a longitudinal muscle layer with a nerve plexus (Fig. 8d). In the posterior 

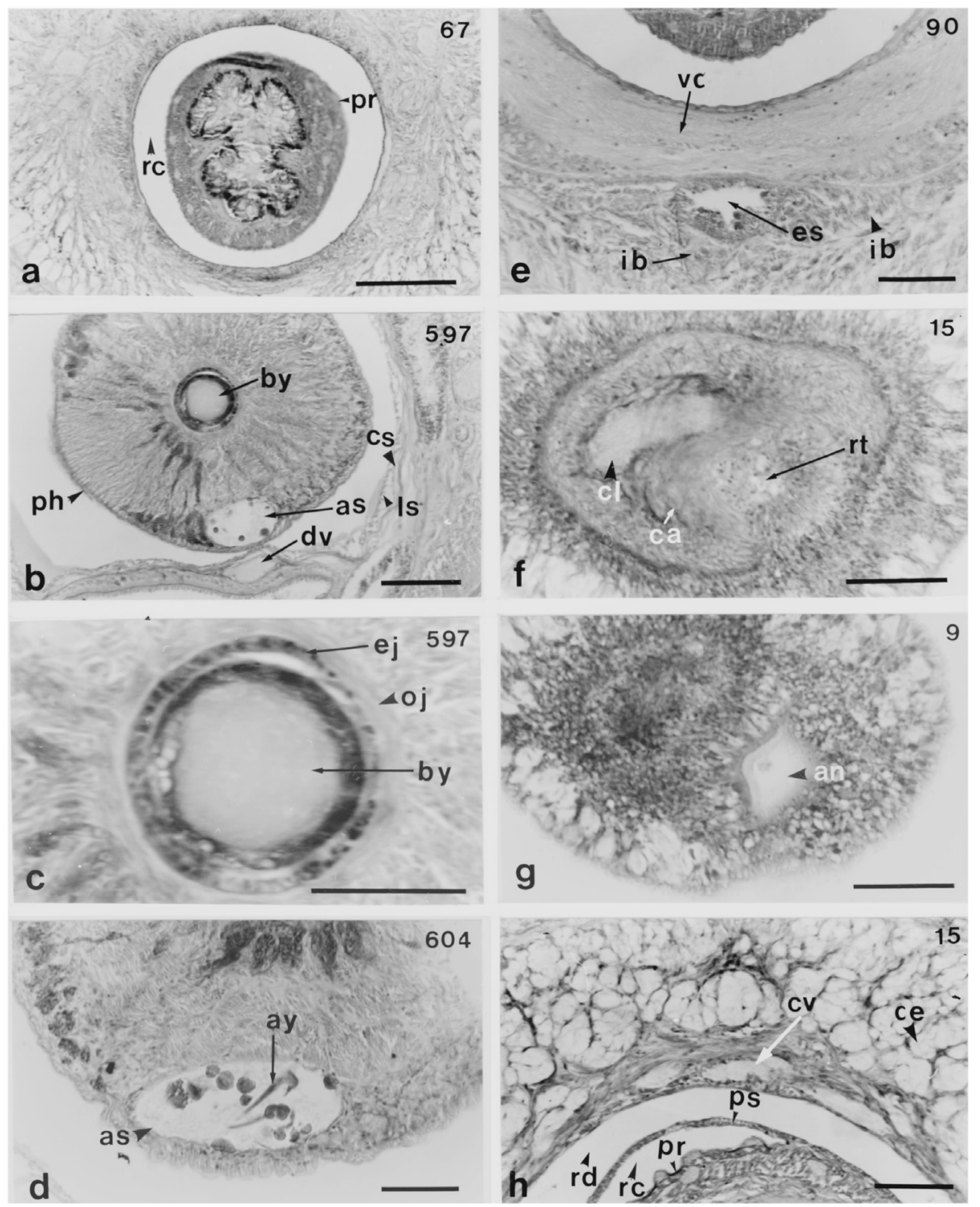

Fig. 9. Amphiporus imparispinosus. Transverse sections between 15-604 from anterior end of body (a-e, h) and 9 and 15 from posterior end of body (f, g), showing (a) rhynchocoel before brain, (b) basis of central stylet and proboscis diaphragm, (c) wall of ductus ejaculatorius and basis of central stylet, (d) accessory stylet pouch, (e) esophagus and ventral commissure of brain, (f) commissure of lateral nerves and rectum, (g) anus, (h) cephalic anastomosis of blood vessel. Scale $50 \mu \mathrm{m}$ (c-e, h) and $100 \mu \mathrm{m}(\mathrm{a}, \mathrm{b}, \mathrm{f}, \mathrm{g})$. an = anus; as = accessory stylet pouch; ay = accessory stylet; by = basis of central stylet; ca = circular muscles of rectum; $\mathrm{ce}=$ cephalic glands; $\mathrm{cl}=$ commissure of lateral nerves; $\mathrm{cs}=$ circular muscle layer of proboscis sheath; $\mathrm{cv}=$ cephalic anastomosis of blood vessel; $\mathrm{dv}=$ dorsal blood vessel; $\mathrm{ej}=$ epithelium of ductus ejaculatorium; es = esophagus; ib = inner longitudinal muscle of body wall; 1 s = longitudinal muscle layer of proboscis sheath; oj = outer circular muscle of ductus ejaculatorius; $\mathrm{ph}=$ proboscis diaphragm; $\mathrm{pr}=$ proboscis; $\mathrm{ps}=$ proboscis sheath; $\mathrm{rc}=$ rhynchocoel; $\mathrm{rd}=$ rhynchodeum; $\mathrm{rt}=$ rectum; $\mathrm{vc}=$ ventral commissure of brain. 
chamber, there is no circular muscle layer.

There are three accessory stylet pouches, each containing several stylets (Fig. 9d). The proboscis has 12 nerves.

\section{Alimentary canal}

The alimentary canal has five major divisions: esophagus, stomach, pylorus, midgut (with anteriorly directed caecum and lateral diverticula), and hindgut. The esophagus opens into the rhynchodeum (Fig. 8f). The distance between the posterior end of the proboscis pore and the mouth is $370 \mu \mathrm{m}$ and that between the mouth and the brain is about $170 \mu \mathrm{m}$; the mouth is therefore located near the transverse level of the brain. Neither the esophagus nor the stomach has longitudinal or circular musculature.

The esophagus, compressed between the rhynchodeum and the cephalic glands on the ventral side of the head, is flattened dorsoventrally. It extends far behind the brain; the distance between the mouth and the posterior end of the esophagus is about $0.7 \mathrm{~mm}$. In the cephalic region, its dorsal side is under the rhynchocoel. There is no obvious space between the esophagus and the ventral commissure of the brain (Fig. 9e). The transitional portion of the esophagus leading into the stomach is about $320 \mu \mathrm{m}$ long. Under the ventral commissure of the brain the esophagus is $80 \mu \mathrm{m}$ wide, its posterior portion $300 \mu \mathrm{m}$ wide.

The stomach, $820 \mu \mathrm{m}$ long and about three times as long as the brain, has eight internal lengthwise folds. Posteriorly, the folds become shorter as the stomach changes into the pylorus. The pylorus is about $3.7 \mathrm{~mm}$ long and about 4.5 times as long as stomach. It is wide and flattened dorsoventrally, being $580 \mu \mathrm{m}$ wide at its junction with the stomach. Just before opening into the midgut, its width narrows to $70 \mu \mathrm{m}$.

The intestinal caecum has a pair of anterior tubular diverticula $2.6 \mathrm{~mm}$ long, and its anterior end extends to the level of posterior end of the brain ( $80 \mu \mathrm{m}$ long). The caecum has 15 pairs of lateral diverticula; these do not branch laterally. The intestine also has lateral diverticula that do not branch.

The rectum, $40 \mu \mathrm{m}$ long, is surrounded by thick circular muscles (Fig. 9f). The anus, $40 \mu \mathrm{m}$ long, opens at the posterior end of the body (Fig. 9g).

\section{Blood-vascular system}

The blood vascular system has three longitudinal vessels. The two cephalic blood vessels lateral to the rhynchodeum anastomose above the rhynchodeum immediately behind the proboscis pore at the tip of the head to form the cephalic loop, $160 \mu \mathrm{m}$ wide, $15 \mu \mathrm{m}$ high, and $30 \mu \mathrm{m}$ long (Fig. 9h). Farther posteriorly, however, both cephalic vessels extend along the dorsolateral portions of the rhynchodeum and turn medially $100 \mu \mathrm{m}$ anterior to the brain (Fig. 10a, b). They enter the brain ring and then run alongside the rhynchocoel. The cephalic vessels, which are located above the cerebral sensory organs, do not become broadened posterior to these (Fig. 10c).

The left cephalic vessel joins the dorsal vessel in the posterior portion of the brain, where the dorsal and ventral fiber cores are separated, then enters the proboscis sheath as a single median vascular plug (Fig. 10d). This plug, about $40 \mu \mathrm{m}$ long, continues posteriorly under the proboscis sheath between the rhynchocoel and the alimentary canal. The three post-cerebral vessels are not linked by pseudometameric transverse connectives.

Behind the brain, the lateral vessels enter the nephridial region through a thick connective, which extends from the level of the posterior end of the brain to the end of the pylorus (Fig. 10e). There are no transverse anastomoses of the lateral vessels in the intestinal region.

Near the posterior end of the body, just anterior to the commissure of the lateral nerves, the blood vessels unite to form a single transverse vessel (Fig. 10f). This anastomosis is $110 \mu \mathrm{m}$ posterior to the end of the rhynchocoel. 

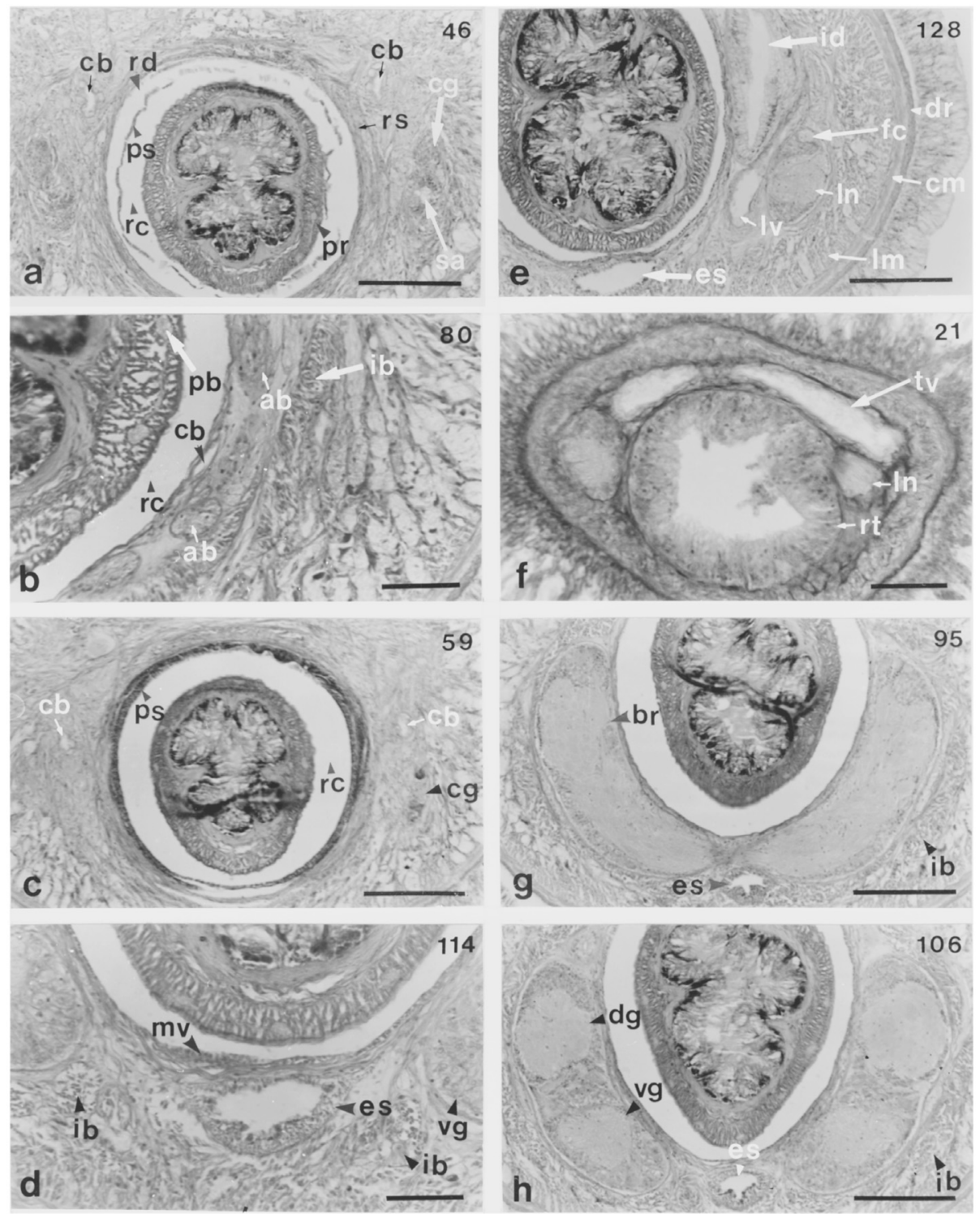

Fig. 10. Amphiporus imparispinosus. Transverse sections between 46-128 from anterior end of body (a-e, g, h) and 21 from posterior end of body (f), showing (a) cephalic blood vessels running along dorsolateral portions of rhynchodeum, (b) cephalic blood vessel running between rhynchocoel and brain, (c) cephalic blood vessels, (d) single median vascular plug, (e) lateral blood vessel between lateral nerve and intestinal diverticulum, (f) transverse blood vessel near the posterior end of the body, (g) brain, (h) dorsal and ventral ganglia. Scale $50 \mu \mathrm{m}$ (b, d, f) and $100 \mu \mathrm{m}$ (a, c, e, g, h). ab = anterior end of brain; br = brain; cb = cephalic blood vessel; $\mathrm{cg}=$ cerebral sensory organ; $\mathrm{cm}=$ circular muscle layer of body wall; $\mathrm{dg}=\mathrm{dorsal}$ ganglion; $\mathrm{dr}=$ dermis; es =esophagus; $\mathrm{fc}=$ fiber core of accessory lateral nerve cord; $\mathrm{ib}=$ inner longitudinal muscle of body wall; id = intestinal diverticula; $1 \mathrm{~m}=$ longitudinal muscle layer of body wall; ln = lateral nerve cord; $l v=$ lateral blood vessel; $\mathrm{mv}=$ median vascular $\mathrm{plug} ; \mathrm{pb}=$ proboscis nerve; $\mathrm{pr}=$ proboscis; $\mathrm{ps}=$ proboscis sheath; $\mathrm{rc}=$ rhynchocoel; $\mathrm{rd}=$ rhynchodeum; $\mathrm{rs}=$ rhynchodeal sphincter; $\mathrm{rt}=$ rectum; sa = sensory canal; $\mathrm{tv}=$ transverse blood vessel; $\mathrm{vg}=$ ventral ganglion. 
Nervous system

The cerebral ganglia, in transverse sections, have a U-shaped configuration (Fig. 10g). They are covered with a thin layer of fibrous connective tissue, are slender dorsoventrally ( $280 \mu \mathrm{m}$ long), and have neither neurochord cells nor an inner neurilemma. Behind the ventral commissure of the brain, the fiber cores of the brain are not separated for a distance of $50 \mu \mathrm{m}$ and successively the fiber cores of the dorsal and ventral ganglia are divided for a distance of $60 \mu \mathrm{m}$ (Fig. 10g, h). The dorsal ganglia do not branch posteriorly into dorsal and ventral lobes. The ventral ganglia, behind the posterior ends of the dorsal ganglia, give rise to the lateral nerve cords.

The right and left ganglia are connected by a long dorsal commissure $15 \mu \mathrm{m}$ thick and $40 \mu \mathrm{m}$ long, and by a longitudinal ventral commissure $40 \mu \mathrm{m}$ thick and $65 \mu \mathrm{m}$ long; the latter is situated at the portion slightly posterior $(20 \mu \mathrm{m})$ to the dorsal commissure (Figs. 9e, 11a).

The lateral nerve cords, which lack myofibrillae but do have a small fiber core of the accessory lateral nerve cord on the dorsal side, give off peripheral nerves; the first of these is at the level of the posterior portion of the esophagus (Fig. 11b). The fiber core begins as a nerve cord from the dorsal ganglion and then joins the ventral ganglion (Fig. $11 \mathrm{c}, \mathrm{d}$ ). In the pyloric region, the lateral nerve cords lie in the parenchyma between the lateral diverticula of the intestinal caecum and the longitudinal musculature of the body wall. A mid-dorsal nerve lies between the dermis and the circular muscle layer of the body wall (Fig. 8a). It does not extend anteriorly beyond the brain. Above the rectum, the lateral nerves are connected by a commissure (Fig. 9f).

The anterior end of the brain gives rise to three nerve cords that innervate various structures of the head on each side (Fig.10b). The upper one extends anteriorly and innervates the eyes, frontal organ, and cephalic glands; the middle one is a proboscis nerve trunk running directly to the portion (100 $\mu$ $\mathrm{m}$ ) where the proboscis is inserted (Fig. 11e); the lower one extends along the lateral side of the esophagus. Rhynchodeal nerves were not observed.

\section{Sensory organs}

The eyes are distributed in two groups confined to an area $550 \mu \mathrm{m}$ long between the posterior end of the proboscis pore and the anterior end of the brain. There are 15 in both the right and left groups. The eyes are of the inverted pigment-cup type and are up to $35 \mu \mathrm{m}$ wide and $40 \mu \mathrm{m}$ high (Fig. 11f). There is large nucleus in the center of each eye.

The frontal glands, above the proboscis pore, extend posteriorly for a distance of $60 \mu \mathrm{m}$ (Fig. $11 \mathrm{~g}$ ); the posterior end of the mass is separated by a distance of about $130 \mu \mathrm{m}$ from the opening of the cerebral sensory organs. In the anterior region of the frontal organ, a large mass of glands is located above the proboscis pore (Fig. 11h). The opening of the frontal organ is situated at the dorsal side of the anterior tip of the head.

The cephalic glands occupy an area of $0.9 \mathrm{~mm}$ long between the anterior tip of the head and the posterior end of the brain; they are especially well developed around the proboscis pore and on the lateral sides of the head, but are absent on the dorsal and ventral sides of the brain. There are no subepithelial glands.

The small cerebral sensory organs, $130 \mu \mathrm{m}$ long, are not covered by fibrous connective tissue like that around the brain, and are separated from the brain for $130 \mu \mathrm{m}$. They are nearly elliptical in transverse section (150 $\mu \mathrm{m}$ high and $70 \mathrm{~mm}$ wide in their middle portions) and consist of a central sensory canal, a ganglionic mass situated at the dorsal and ventral sides, and three cyanophilous glandular masses, which are arranged dorsoventrally and posteriorly reduced to a small mass (Fig. 12a-f). A nerve of the cerebral sensory organ extends from its posterior end of the organ to the dorsal ganglion, a distance of $400 \mu \mathrm{m}$; it is not clearly observed except near the anterior end of the brain.

The cerebral organ canal, ciliated and $80 \mu \mathrm{m}$ long, begins on the lateroventral side of the head about $240 \mu \mathrm{m}$ from the anterior tip. It runs obliquely to the cerebral organ (Fig. $12 \mathrm{~g}, \mathrm{~h}$ ). The epithelium of the canal is $15 \mu \mathrm{m}$ thick. Before the canal enters the cerebral organ, it does not widen, and it does not have a U-shaped ciliated sensory portion. The sensory canal that succeeds the cerebral 

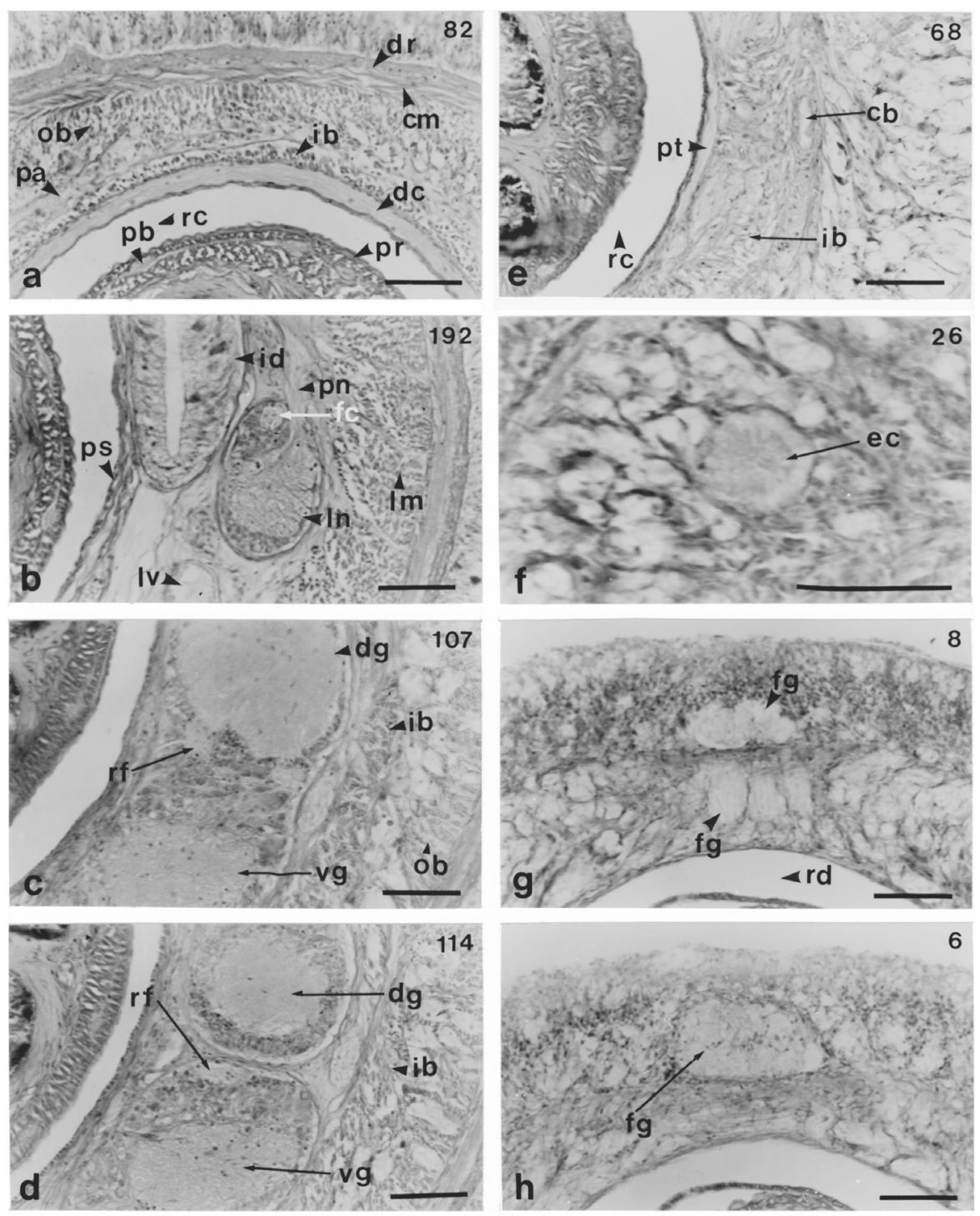

Fig. 11. Amphiporus imparispinosus. Transverse sections between 6-192 from anterior end of body (a-h), showing (a) inner longitudinal muscle of body wall and dorsal commissure of brain, (b) fiber core of accessory lateral nerve cord and peripheral nerve, (c) rudiment of fiber core of accessory lateral nerve cord in dorsal ganglion of brain, (d) rudiment of accessory lateral nerve cord in ventral ganglion of brain, (e) inner longitudinal muscle of body wall for the proboscis insertion and the proboscis nerve trunk, (f) eye, (g) frontal glands, (h) large mass of frontal glands. Scale $50 \mu \mathrm{m}(\mathrm{a}-\mathrm{h}) . \mathrm{cb}=$ cephalic blood vessel; $\mathrm{cm}=$ circular muscle layer of body wall: $\mathrm{dc}=$ dorsal commissure of brain; $\mathrm{dg}=$ dorsal ganglion; $\mathrm{dr}=\mathrm{dermis}$; ec $=$ eye; $\mathrm{fc}=$ fiber core of accessory lateral nerve cord; $\mathrm{fg}=$ frontal glands; $\mathrm{ib}=$ inner longitudinal muscle of body wall; id = intestinal diverticulum; $1 \mathrm{~m}=$ longitudinal muscle layer of body wall; $1 \mathrm{n}=$ lateral nerve; $1 \mathrm{v}$ $=$ lateral blood vessel; $\mathrm{ob}=$ outer longitudinal muscle of body wall; $\mathrm{ec}=\mathrm{eye} ; \mathrm{pa}=$ parenchyma; $\mathrm{pb}=$ proboscis nerve; $\mathrm{pn}=$ peripheral nerve; $\mathrm{pr}=$ proboscis; $\mathrm{ps}=$ proboscis sheath; $\mathrm{pt}=$ proboscis nerve trunk; $\mathrm{rc}=$ rhynchocoel; $\mathrm{rd}=$ rhynchodeum; $\mathrm{rf}=$ rudiment of fiber core of accessory nerve cord; $\mathrm{vg}=$ ventral ganglion. 

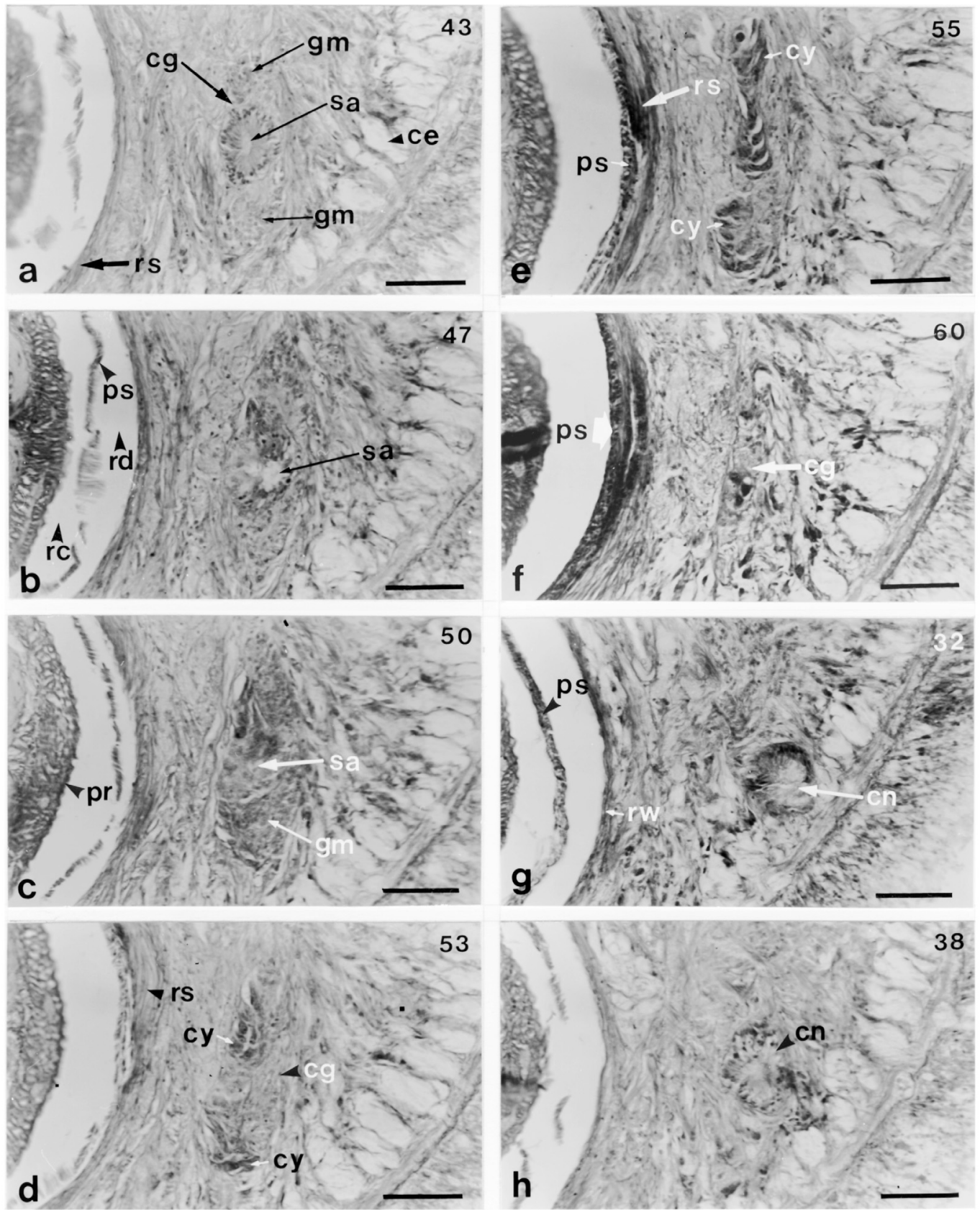

Fig. 12. Amphiporus imparispinosus. Transverse sections between 32-60 from anterior end of body (a-h), showing (a-c) sensory canal and ganglionic mass of cerebral sensory organ, (d-f) cyanophilic glandular mass and proboscis insertion by which the proboscis sheath is separated, (g and h) cerebral organ canal. Scale $50 \mu$ $\mathrm{m}(\mathrm{a}-\mathrm{h})$. ce = cephalic glands; $\mathrm{cg}=$ cerebral sensory organ; $\mathrm{cn}=$ cerebral organ canal; $\mathrm{cy}=$ cyanophilic glandular mass; $\mathrm{gm}=$ ganglionic mass; $\mathrm{pr}=$ proboscis; $\mathrm{ps}=$ proboscis sheath $; \mathrm{rc}=$ rhynchocoel; $\mathrm{rd}=$ rhynchodeum; rs = rhynchodeal sphincter; rw = rhynchodeum wall; sa = sensory canal. 
organ canal is surrounded by a mass of ganglionic cells (Fig. 12c).

Excretory and reproductive systems

The excretory system is well developed, extending from the posterior portion of the brain to the level of the end of the pylorus. The efferent ducts, which are paired, are short but conspicuous and extend laterally to the lateral nerve cords. The excretory pores, lateral or slightly dorsal to the nerve cords, are widely scattered in the nephridial region; there are two on the right side of the body and five on the left side. In the specimen collected at San Juan Island, there were four on the right side of the body and five on the left side.

The female gonads are immature. Their gonoducts open on the dorsolateral surfaces of the body.

Systematic Discussion

Amphiporus imparispinosus was established by Griffin in 1898, and descriptions of this species were successively made by Coe (1905) and Correa (1964). Amphiporus leuciodus, established by Coe in 1901 and noted by Punnett in 1901, is synonymous with A. imparispinosus (Coe, 1904). Thollesson and Norenburg (2003) accepted A. imparispinosus Griffin, 1898 as a member of the Family Amphiporidae.

Coe $(1901,1905)$ reported that the several anterior efferent nephridial ducts open ventrolaterally and others dorsoventrally. This is at variance with my observations.

Amphiporus imparispinosusis easily distinguished from A. formidabilis by its body size, coloration, and armature of the proboscis.

The accessory lateral nerve cords in the specimens collected at Rock point, Lopez Island and San Juan Island are the first to be observed in any species of Amphiporidae. Gibson and Sundberg (1992), however, reported the accessory lateral nerve cords in the marine hoplonemertean Pantinonemertes daguilarensis in the family Prosorhochmidae.

\section{Nipponnemertes punctatula $(\mathrm{Coe}, 1905)$}

(Pl. 1, figs. 3, 4; Fig. 1f-j; Figs. 13-18)

Amphiporus punctatulus Coe, 1905: p. 253-259, pl. 21, figs. 129-140, pl. 24, fig. 194; Iwata, 1951: p. 138, fig. 23; Iwata, 1952: p. 143-144; Iwata, 1954a: p. 39; Iwata, 1954b: 22-23; Iwata, 1957: p. 21-22; Gibson, 1995: p. 292.

Amphiporus nebulosus Coe, 1901: p. 48-51, text-fig. 12, pl. 4, fig. 1, pl. 8, fig. 6, pl. 11, fig. 1; Takakura, 1933: p. 226; Gibson and Crandall, 1989: p. 466, 467; Gibson, 1995: p. 289, 290.

Nipponnemertes punctatulus Friedrich, 1968: p. 34; Gibson, 1995: p. 442.

Nipponnemertes punctatula Yamaoka, 2005: p. 149-150.

\section{Material}

One specimen is deposited at the National Museum of Natural History, Smithsonian Institution, Washington, DC. USA.

One specimen (female) consisting of 32 slides of stained sections, including 19 slides of the head region, five slides of the tail portion, and eight slides of the proboscis. The rest of the body and a piece of the proboscis were not sectioned.

One specimen (male) consisting of 40 slides of stained serial sections, including 13 slides of the head region, ten slides of the middle region, ten slides of the tail portion, and seven slides of the proboscis. Two pieces of the body and a long piece of the proboscis were not sectioned.

\section{Locality}

One specimen (female) (Pl. 1, fig. 3; Fig. 1f, g), collected by dredging at Mineral Point, San Juan Island (Lat. $48^{\circ} 35,8^{\prime} \mathrm{N}$, Long. $123^{\circ} 4.4^{\prime} \mathrm{W}$ ) at a depth of 30 fathoms on August 24, 1964 and the two 
specimens, collected by dredging in San Juan Channel (Lat. 34, $3^{\prime} \mathrm{N}$, Long. $123^{\circ} 1.7^{\prime} \mathrm{W}$ ) at a depth of 62 fathoms on October 21, 1964.

\section{External features}

The specimen (female) collected at Mineral Point, San Juan Island was about $3 \mathrm{~cm}$ long by $2 \mathrm{~mm}$ wide (Pl. 1, fig. 3). On the dorsal side, it was pale brown, with numerous darker spots and whitish ventrally. The head was white with two dark markings consisting of crowded brown dots. The cephalic furrows had sagittally-ridged secondary cephalic grooves, like those of the specimens collected in Japan (Fig. 1f, g). The proboscis, when extruded, was long and transparent, with a pinkish stylet basis and two accessory stylet pouches. There were two groups of eyes bordering the dorsal markings of the head and also a few eyes behind the cephalic furrows (Fig. 1f).

In the two specimens collected in San Juan Channel, one was about $10 \mathrm{~cm}$ long by $4 \mathrm{~mm}$ wide (Pl. 1, fig. 4; Fig. 1h-j) and the other (male) was about $6 \mathrm{~cm}$ long by $2.5 \mathrm{~mm}$ wide. The color was light yellowish white, with numerous brown spots on the dorsal side. The head was white with a pair of dark brown blotches, and was separated from the rest of the body by a transverse white band, which contained the sagittally-ridged cephalic grooves (Fig.1h-j). The opening of the cerebral organ canal could be seen between the ends of the dorsal and ventral cephalic grooves (Fig. 1i, j). The marginal eyes on the head were arranged in two groups, and there were a few eyes behind the cephalic furrows (Fig. 1h, i).

Body wall, musculature, and parenchyma

In the pyloric region, the epidermis contains elliptical unicellular glands thickly arranged in a row; in the cephalic region, however, single glands are confined to the upper area of the layer. The body wall musculature, especially its longitudinal layer, is well developed, with a layer of diagonal muscles between circular and longitudinal muscles (Fig. 13a). The dermis is $60 \mu \mathrm{m}$ thick on the dorsal side of the pyloric region. The outer circular muscle layer is $40 \mu \mathrm{m}$ thick, while the inner longitudinal muscle layer is 2.5 times as thick, averaging $100 \mu \mathrm{m}$. The longitudinal layer is not divided anteriorly by connective tissue, and there are no cephalic retractor muscles. Dorsoventral muscles and parenchyma are absent.

Rhynchodeum, rhynchocoel, and proboscis

The proboscis pore, about $120 \mu \mathrm{m}$ long, is situated at the anterior end of the head under the frontal organ, which consists of an elongated mass of glands posterior to its opening (Fig. 13b, c). The pore is a shallow vertical groove, $180 \mu \mathrm{m}$ deep at its posterior end (Fig. 13d). The rhynchodeum behind the proboscis pore is circular in transverse section, $100 \mu \mathrm{m}$ in diameter, and composed of a thick wall $(10 \mu \mathrm{m})$ with crowded cilia (Fig. 13e).

At a transverse level $150 \mu \mathrm{m}$ posterior to the proboscis pore, the rhynhchodeum becomes conspicuously enlarged, $140 \mu \mathrm{m}$ by $60 \mu \mathrm{m}$ in diameter (Fig. 13f); its wall, $10 \mu \mathrm{m}$ thick and with few cilia, is covered by a layer of longitudinal muscles derived from the longitudinal muscle layer of the body wall. The diameter of this part of the rhynchodeum, which is $200 \mu \mathrm{m}$ long, becomes smaller and then disappears into the rhynchodeum, which becomes elliptical, $100 \mu \mathrm{m}$ by $70 \mu \mathrm{m}$ in diameter. The muscular rhynchodeal sphincter is $70 \mu \mathrm{m}$ thick (Fig. 13g).

Another enlargement of the rhynchodeum occurs at a distance of $110 \mu \mathrm{m}$ posterior to the first one. It is $200 \mu \mathrm{m}$ high and $150 \mu \mathrm{m}$ wide and also has a thick layer of the rhynchodeal sphincter (Fig. 13h). The precerebral septum of the proboscis behind the secondary enlargement of the rhynchodeum is of the closed type and consists of 10 loosely-arranged bundles of longitudinal muscles on the dorsal side of the rhynchodeum (Fig. 14a). These muscles are derived from the longitudinal muscle layer of the cephalic region. Between the bundles of longitudinal muscles there are found the rudiments of the proboscis nerves, which posteriorly enter the wall of the proboscis (Fig. 14b). The precerebral septum 

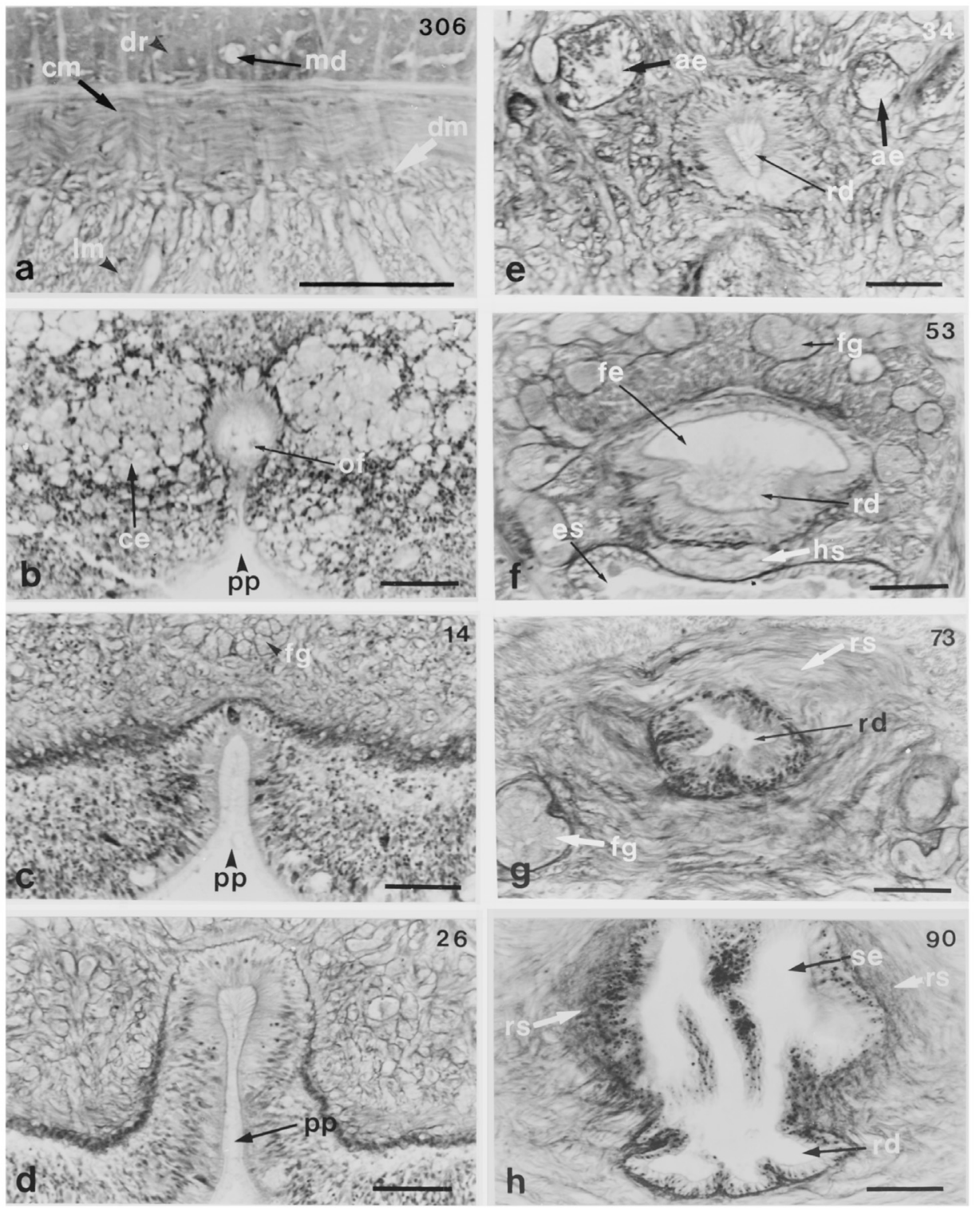

Fig. 13. Nipponnemertes punctatula. Transverse sections between 34-306 from anterior end of body (a-h), showing (a) middorsal nerve and diagonal muscle layer, (b) opening of frontal organ and proboscis pore, (c) frontal glands and proboscis pore, (d) proboscis pore, (e) rhynchodeum behind proboscis pore and anterior portions of esophagus, (f) rhynchodeum enlarged primarily, horizontal sheet, and frontal glands, (g) rhynchodeum and rhynchodeal sphincter, (h) rhynchodeum enlarged secondarily. Scale $50 \mu \mathrm{m}(\mathrm{a}-\mathrm{h})$. ae = anterior portions of esophagus; $c e=$ cephalic glands; $\mathrm{cm}=$ circular muscle layer of body wall; $\mathrm{dm}=$ diagonal muscle layer; $\mathrm{dr}=$ dermis; es = esophagus; fe = rhynchodeum enlarged primarily; fg = frontal glands; hs = horizontal sheet between esophagus and rhynchodeum; $1 \mathrm{~m}=$ longitudinal muscle layer of body wall; $\mathrm{md}=$ middorsal nerve; of = opening of frontal organ; $\mathrm{pp}=$ proboscis pore; $\mathrm{rd}$ = rhynchodeum; rs = rhynchodeal sphincter; se = rhynchodeum enlarged secondarily. 

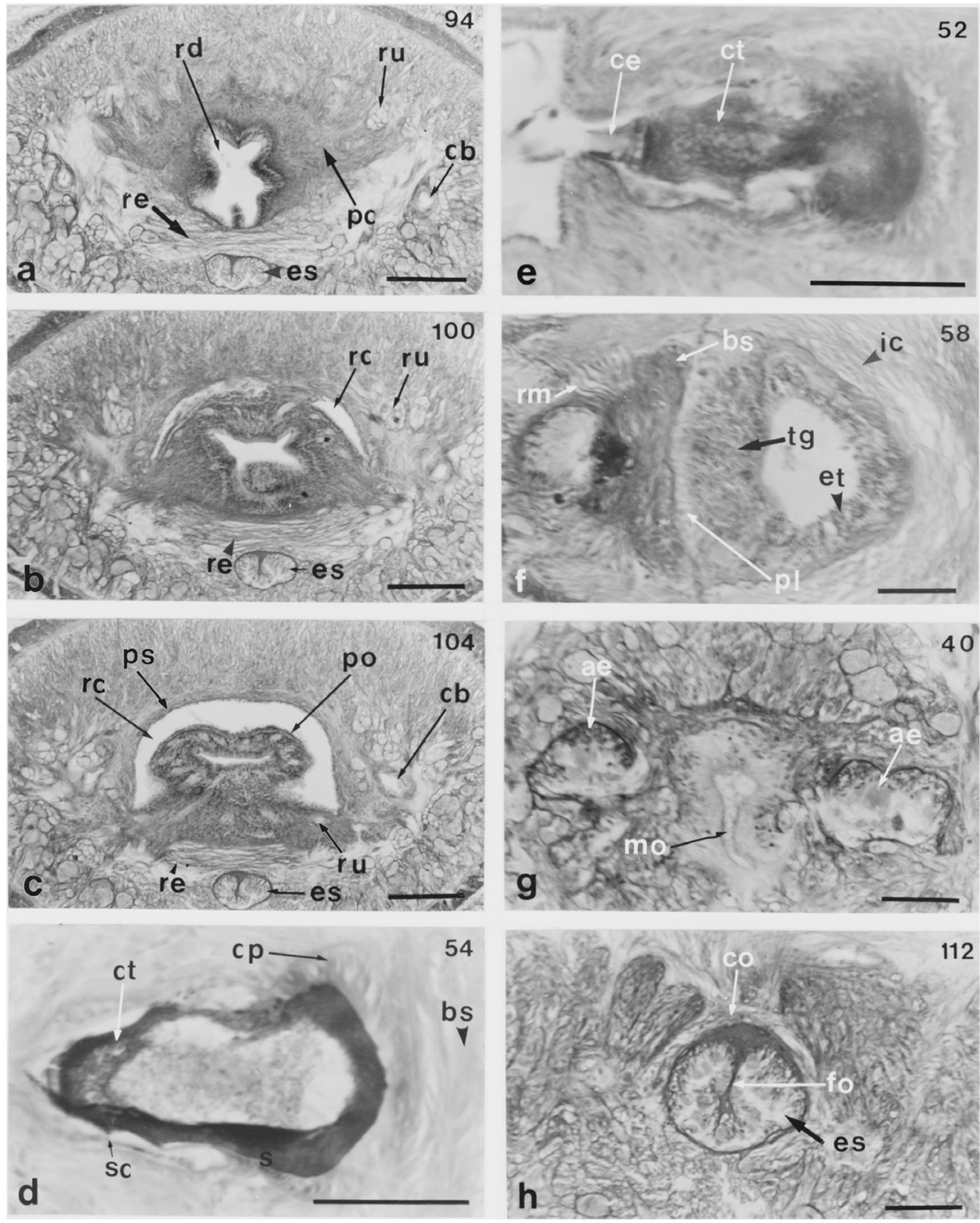

Fig. 14. Nipponnemertes punctatula. Transverse sections between 40-112 from anterior end of body (a-c, g, h) and frontal sections between 52-58 of proboscis apparatus (d-f), showing (a) precerebral septum of proboscis on the dorsal side of rhynchodeum and rhynchodeal sphincter between the rhynchodeum and the esophagus, (b) proboscis insertion by which proboscis nerves enter the proboscis, (c) proboscis sheath and proboscis with 15 proboscis nerves, (d) basis of central stylet, cap-like tissue, and flattened bolster, (e) basis of central stylet and central stylet lacking the anterior portion, (f) construction of stylet bulb, (g) mouth, anterior portions of esophagus, and frontal glands, (h) circular muscles surrounding the esophagus. Scale $50 \mu \mathrm{m}(\mathrm{d}-\mathrm{h})$ and $100 \mu \mathrm{m}(\mathrm{a}-\mathrm{c})$. ae $=$ anterior portions of esophagus; bs = bolster; $\mathrm{cb}=$ cephalic blood vessel; $\mathrm{ce}=$ central stylet; $\mathrm{co}=$ circular muscle of esophagus; $\mathrm{cp}=$ cap-like tissue of the basis of the central stylet; $\mathrm{ct}=$ central stylet basis; es = esophagus; et $=$ eosinophilic epithelium; fo $=$ fold of esophagus; ic $=$ interlacing circular muscles; $\mathrm{mo}=$ mouth; $\mathrm{pc}=$ precerebral septum of proboscis; $\mathrm{pl}=$ plate like epithelial wall; po = proboscis in rhynchocoel; $\mathrm{ps}=$ proboscis sheath; $\mathrm{rc}=$ rhynchocoel; $\mathrm{rd}=$ rhynchodeum; re $=$ rhynchodeal sphinctor between the rhynchodeum and the esophagus; $r m=$ retractor muscle of the basis of the central stylet; ru = rudiment of proboscis nerve; $\mathrm{sc}=$ string like connections; $\mathrm{tg}$ $=$ dense layer of glandular cells. 
on the ventral side of the rhynchodeum appears as a muscular bundle flattened dorsoventrally; five proboscis nerves enter the proboscis (Fig. 14c). The rhynchocoel behind the precerebral septum has a wickerwork of interwoven circular and longitudinal muscles (Fig. 14c). The distance between the anterior end of the rhynchodeum and the precerebral septum is $500 \mu \mathrm{m}$. At the proboscis insertion, 15 proboscis nerves were counted in this specimen (Fig. 14c).

The pressure of the body-wall longitudinal muscles caused the rhynchocoel wall to buckle inward into a fold that protruded into the lumen of the rhynchocoel, forming a dorsal ridge (Fig. 16b).

The proboscis diaphragm has central stylet apparatus consisting of a pear-shaped basis about 110 $\mu \mathrm{m}$ long and $60 \mu \mathrm{m}$ wide; it is about 2.5 times as long as a stylet (Fig. $14 \mathrm{~d}$, e). The basis of the central stylet does not have a posteriorly-inserted accessory stylet. The anterior portion of the basis has stringlike connections with the wall of the proboscis diaphragm, but the posterior bulbous part is tightly bound to the cap-like tissue (Fig. 14d). The basis itself consists of an outer wall about $10 \mu \mathrm{m}$ thick and deeply stained in red, while inside the wall there is loose connective tissue. The basis rests on a flattened bolster, $30 \mu \mathrm{m}$ thick and $150 \mu \mathrm{m}$ wide, consisting of interwoven circular and longitudinal muscles (Fig. 14d, f). It has bundle of retractor muscles arranged obliquely between the longitudinal musculature of the proboscis diaphragm and the bolster (Fig. 14f). Posterior to the bolster, the stylet bulb has a platelike epithelial wall, a thick layer of glandular cells in its anterior portion, eosinophilous connective tissue $20 \mu \mathrm{m}$ thick, and interlacing circular muscles about $130 \mu \mathrm{m}$ thick (Fig. 14f). There are two accessory stylet pouches, one with three stylets, the other with two. The proboscis has 12 nerves. In the specimen collected in San Juan Channel, there are 16 nerves.

The rhynchocoel ends a short distance $(70 \mu \mathrm{m})$ anterior to the posterior nerve anastomosis.

\section{Alimentary canal}

The mouth, $40 \mu \mathrm{m}$ long, opens into the rhynchodeum and has a length of $70 \mu \mathrm{m}$ long up to the proboscis pore (Fig. 14g). The esophagus does not have a caecum, but has circular muscle for a short distance anterior to the brain (Fig. 14h). This muscle is derived from a horizontal circular muscle plate running under the rhynchocoel in front of the brain; it is $40 \mu \mathrm{m}$ thick and $40 \mu \mathrm{m}$ long (Fig. 15a).

The esophagus immediately behind the mouth is flattened dorsoventrally, $270 \mu \mathrm{m}$ wide and 50 $\mu \mathrm{m}$ high (Fig. 15b). The swollen pouchlike portions at the lateral sides of the esophagus extend anteriorly up to the lateral sides of the frontal glands, a distance of $140 \mu \mathrm{m}$ (Figs. $14 \mathrm{~g}, 15 \mathrm{~b}, \mathrm{c}$ ). The esophagus, $800 \mu \mathrm{m}$ long, becomes gradually narrowed until it appears as a tubular gut with a diameter of $80 \mu \mathrm{m}$ at the level of the anterior end of the brain (Figs. 14h, 15d). It has glands and fine cilia in the epithelium and several masses of longitudinal muscles cover it entirely (Fig. 15d, h). In the middle region of the esophagus, there is a shallow fold on the dorsal side of the esophagus (Fig. 15h); it becomes deeper at the level of the anterior end of the brain (Fig. 14h).

Between the esophagus and the rhynchodeum, a thin platelike horizontal sheet is present for a distance of $60 \mu \mathrm{m}$ posterior to the mouth (Fig. 15e). It is $90 \mu \mathrm{m}$ wide and $10 \mu \mathrm{m}$ thick and consists of a layer of cells that are not stained. At a distance of $50 \mu \mathrm{m}$ posteriorly, where the first enlargement of the rhynchodeum occurs, it becomes thicker and consists of two layers of cells (Fig. 15f). The smallest sheet is seen in Fig. 15g.

A transverse sheet of circular muscle is inserted between the rhynchodeum and the esophagus, where the rhynchodeum is surrounded by the thick layer of the rhynchodeal sphincter (Fig. 15h). The muscular sheet thus formed is fused posteriorly with the rhynchodeal sphincter on the precerebral septum of the proboscis in front of the brain (Fig. 14a).

In the region of the brain, the esophagus is in contact with the ventral commissure of the brain. It is columnar in construction and the mid-dorsal fold is elongated vertically (Fig. 16a). The transitional area of the stomach is recognizable by the mid-dorsal fold running obliquely (Fig. 16b). The transition of the esophagus into the stomach, $210 \mu \mathrm{m}$ long, continues until the level of the posterior part of the brain, where three large and long folds (the mid-dorsal fold appearing last) are present (Fig. 16c).

The stomach, $870 \mu \mathrm{m}$ long, has eight folds originating from the three folds in the transitional 

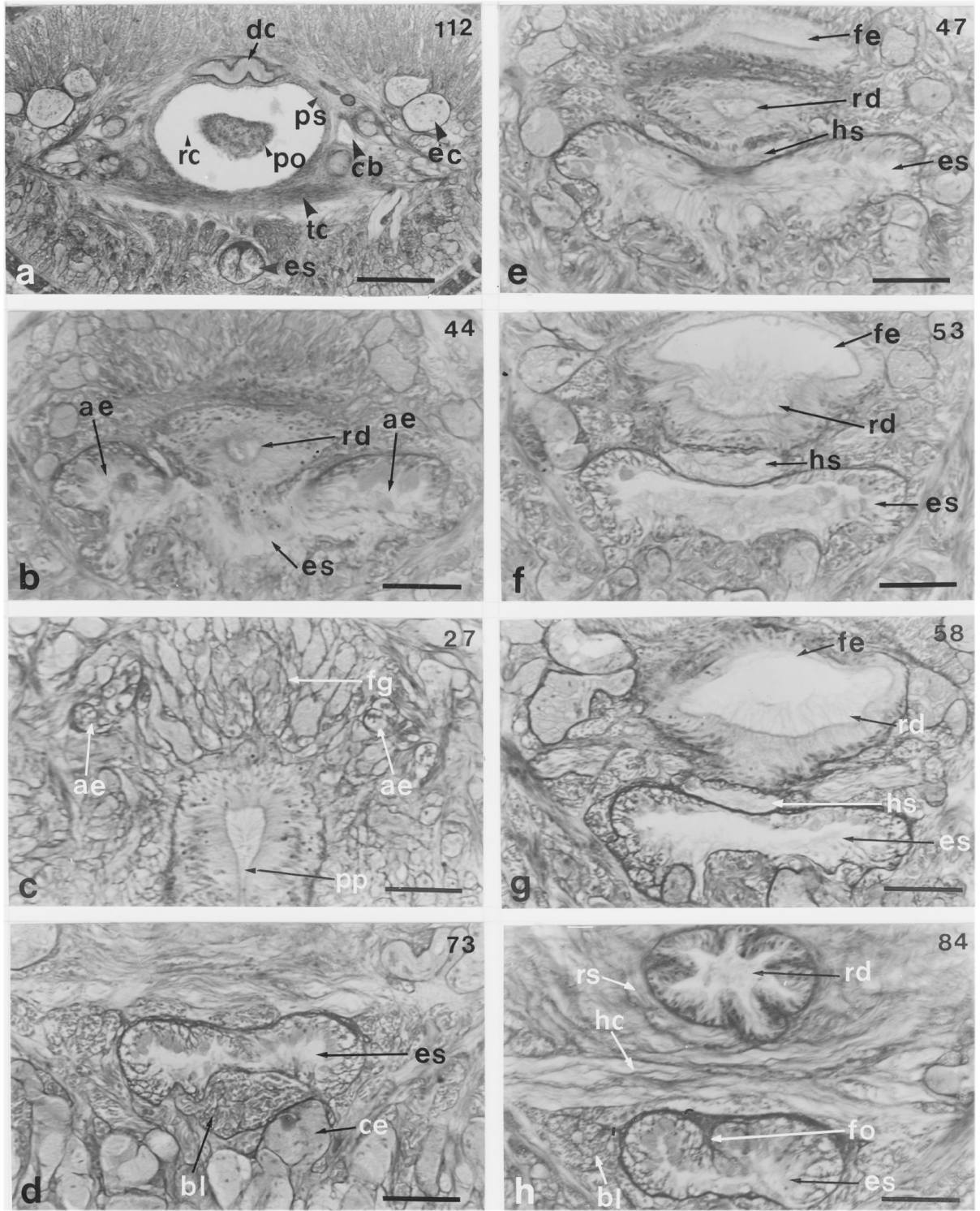

Fig. 15. Nipponnemertes punctatula. Transverse sections between $27-112$ from anterior end of body (a-h), showing (a) horizontal plate of circular muscle in front of brain, (b) esophagus behind mouth, (c) anterior portions of esophagus on the lateral sides of frontal glands, (d) esophagus surrounded by several masses of longitudinal muscle, (e) anterior end of horizontal sheet between the rhynchodeum and the esophagus, (f) horizontal sheet composed of two rows of cell, (g) posterior end of horizontal sheet, (h) transverse plate of circular muscle running horizontally between the rhynchodeal sphincter and the esophagus. Scale $50 \mu \mathrm{m}$ (b-h) and $100 \mu \mathrm{m}$ (a). ae = anterior portions of esophagus; bl = bundles of longitudinal muscle surrounding the esophagus; $\mathrm{cb}=$ cephalic blood vessel; $\mathrm{ce}=$ cephalic glands; $\mathrm{ec}=\mathrm{eye}$; $\mathrm{dc}=\mathrm{dorsal}$ commissure of brain; es = esophagus; $\mathrm{fe}=$ rhynchodeum enlarged primarily; $\mathrm{fg}=$ frontal glands; fo $=$ fold of esophagus; $\mathrm{hc}=$ horizontal plate of circular muscle; hs = horizontal sheet between the esophagus and the rhynchodeum; po = proboscis in rhynchocoel; $\mathrm{pp}=$ proboscis pore; $\mathrm{ps}=$ proboscis $\mathrm{sheath} ; \mathrm{rc}=$ rhynchocoel; $r d$ = rhynchodeum; $r$ s = rhynchodeal sphincter; $t c=$ transverse plate of circular muscle. 

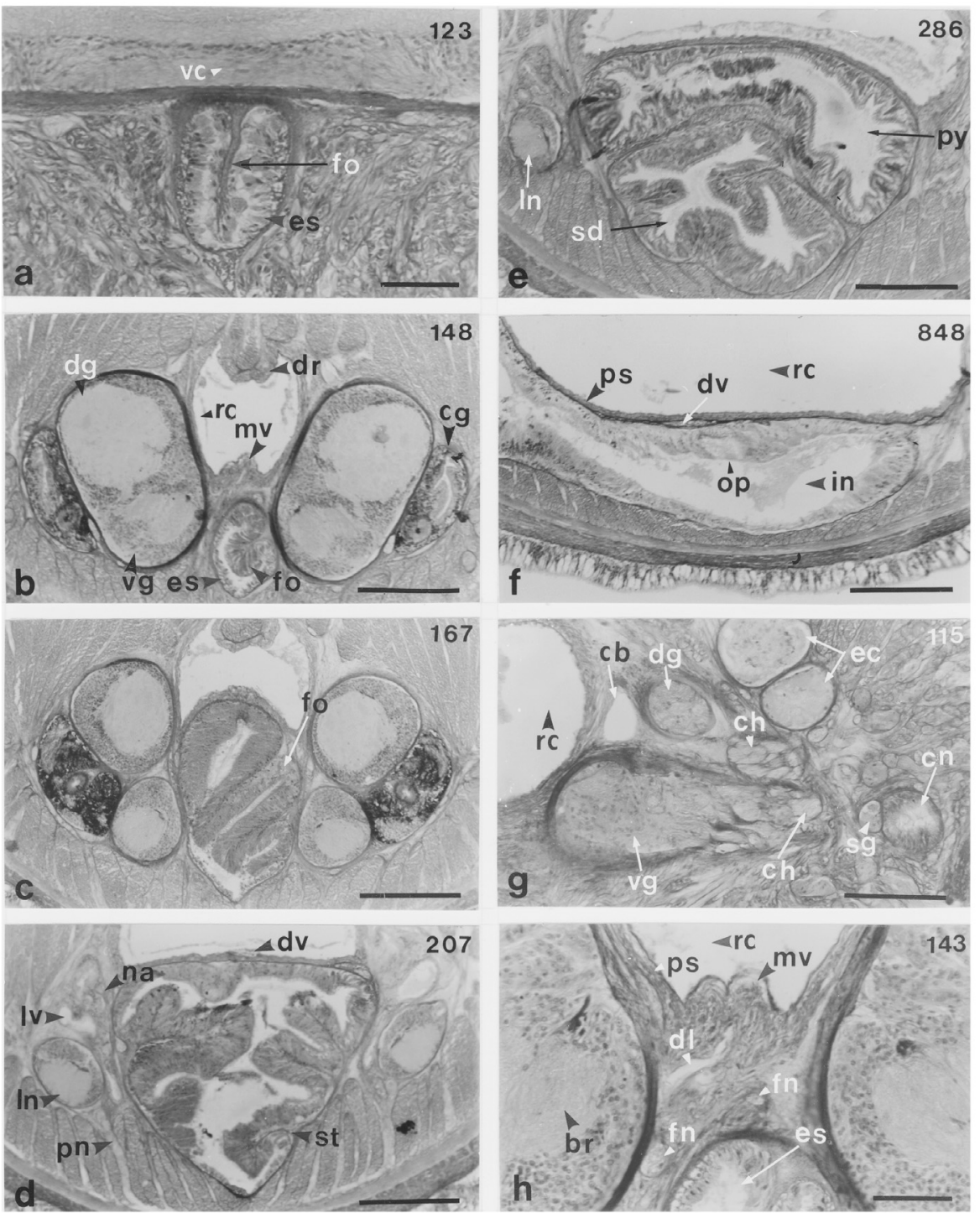

Fig. 16. Nipponnemertes punctatula. Transverse sections between 115-848 from anterior end of body (a-h), showing (a) esophagus under the ventral commissure of brain, (b) transitional portion of the stomach with mid-dorsal fold and dorsal ridge of proboscis sheath, (c) three long folds of esophagus, (d) stomach with eight folds, (e) anterior end of pylorus and stomach diverticulum, (f) opening of pylorus, (g) cephalic blood vessel inside the brain and two cephalic nerves of ventral ganglion, (h) dorsal vessel entering median vascular plug. Scale $50 \mu \mathrm{m}(\mathrm{a}, \mathrm{h})$ and $100 \mu \mathrm{m}(\mathrm{b}-\mathrm{g}) . \mathrm{br}=$ brain; $\mathrm{cb}=$ cephalic blood vessel; $\mathrm{cg}=$ cerebral sensory organ; $\mathrm{ch}=$ cephalic nerves; $\mathrm{cn}=$ cerebral organ canal; $\mathrm{dg}=$ dorsal ganglion; $\mathrm{dl}=\mathrm{dorsal}$ blood vessel separated from left cephalic blood vessel; $\mathrm{dr}=$ dorsal ridge of proboscis sheath; $\mathrm{dv}=\mathrm{dorsal}$ blood vessel; ec = eye; es = esophagus; $\mathrm{fn}=$ foregut nerve; fo = fold of esophagus; in = intestine; $\ln =$ lateral nerve cord; $\mathrm{lv}=$ lateral blood vessel; $\mathrm{mv}=$ median vascular plug; na = nephridia; op = opening of pylorus; $\mathrm{pn}=$ peripheral nerve; $\mathrm{ps}=$ proboscis sheath; py = pylorus; $\mathrm{rc}=$ rhynchocoel; $\mathrm{sd}=$ stomach diverticulum; $\mathrm{sg}=$ small glandular mass of cerebral organ canal; $\mathrm{st}=$ stomach; $\mathrm{vc}=$ ventral commissure of brain; vg = ventral ganglion. 
area of the stomach (Fig. 16d). The transitional region of the stomach into the pylorus, $570 \mu \mathrm{m}$ long, ends where the proper pylorus begins (Fig. 16e). The stomach below the pylorus continues as a diverticulum $720 \mu \mathrm{m}$ long. The pylorus, $4.6 \mathrm{~mm}$ long is long and five times as long as the stomach opens into the intestine (Fig. 16f).

The intestinal caecum has three small pouches at its anterior tip and eight pairs of lateral diverticula; these do not branch laterally. The anterior ends of the pouches are separated from the posterior end of the brain by a distance equal to twice the length of the brain. The anus opens at the posterior end of the body. The rectum, $100 \mu \mathrm{m}$ long, is surrounded by a few circular muscles.

\section{Blood-vascular system}

The blood vascular system has three longitudinal vessels. The two cephalic blood vessels lateral to the rhynchodeum anastomose above the rhynchodeum near the tip of the head to form the cephalic loop (Fig. 17f). Farther posteriorly, the cephalic vessels turn medially in front of the brain. They enter the brain ring without giving off cerebral vessels and then run alongside the rhynchocoel (Fig. 16g). The dorsal vessel, originating from the left cephalic vessel, passes through the rhynchocoel wall to form a median vascular plug on its inner surface (Fig. 16h). Metameric anastomoses are not present. The dorsal vessel immediately anterior to the commissure of the lateral nerves anastomoses with the lateral vessels.

\section{Nervous system}

The brain and lateral nerves are covered by a layer of fibrous connective tissue, but the brain lacks a neurilemma and large ganglion cells (Fig. 17a). The nervous system has no neurochord cells or accessory lateral nerves. The mid-dorsal nerve extends anteriorly beyond the brain (Fig. 17b). The lateral nerve cords have myofibrillae and peripheral nerves (Fig. 17c) and are posteriorly connected to each other by a commissure on the dorsal side of the rectum.

The dorsal commissure (70 $\mu \mathrm{m}$ thick) is situated a short distance $(90 \mu \mathrm{m})$ farther anteriorly than the ventral one. The dorsal ganglia are separated from the ventral ganglia posteriorly. The dorsal ganglia do not have a bifurcated fiber core. A pair of foregut nerves originates from the ventral ganglia immediately behind the ventral commissure, but there is no transverse connective between them.

A proboscis nerve trunk arises from the anterior end of each ventral ganglion and extends anteriorly to the proboscis sheath. Each of these two nerve trunks branches into five nerves, one lying on the latero-ventral side and other four on the dorso-lateral side of the proboscis sheath (Fig. 17d, e). Two large cephalic nerves, arranged one above the other, emerge from the anterior lateral face of each ventral ganglion and proceed anteriorly on the lateral side of the cephalic region (Fig. 16g).

\section{Sensory organs}

The dorsomedial cephalic groove has two epidermal folds (Fig. 17b). The cephalic furrows have secondary grooves between the 16 transverse ridges (Fig. 17b) (cf. Iwata, 2001). The frontal organ and frontal glands are well developed; the former forms a short duct opening at the anterior end of the head (Fig. 13b); the latter does not reach posteriorly to the anterior end of the brain, there being a distance of $260 \mu \mathrm{m}$ between the two organs (Figs. 15c, 17f). The cephalic glands are not well developed and do not reach posteriorly to the cerebral ganglia. Subepithelial glands are prominent on the lateral sides of the brain region (Fig. 18e).

In this specimen (female), 55 eyes form two groups of 13 and 10 (left) and 13 and 14 (right) plus three and two (left and right) behind the cephalic furrows. The eyes are of the inverted pigment-cup type. One of the three left eyes in the anterior end of the brain (Fig. 17g) is $80 \mu \mathrm{m}$ wide and high. There is large nucleus in the center of this eye.

The cerebral sensory organ, without neurilemma, is $750 \mu \mathrm{m}$ long and extends posteriorly behind 

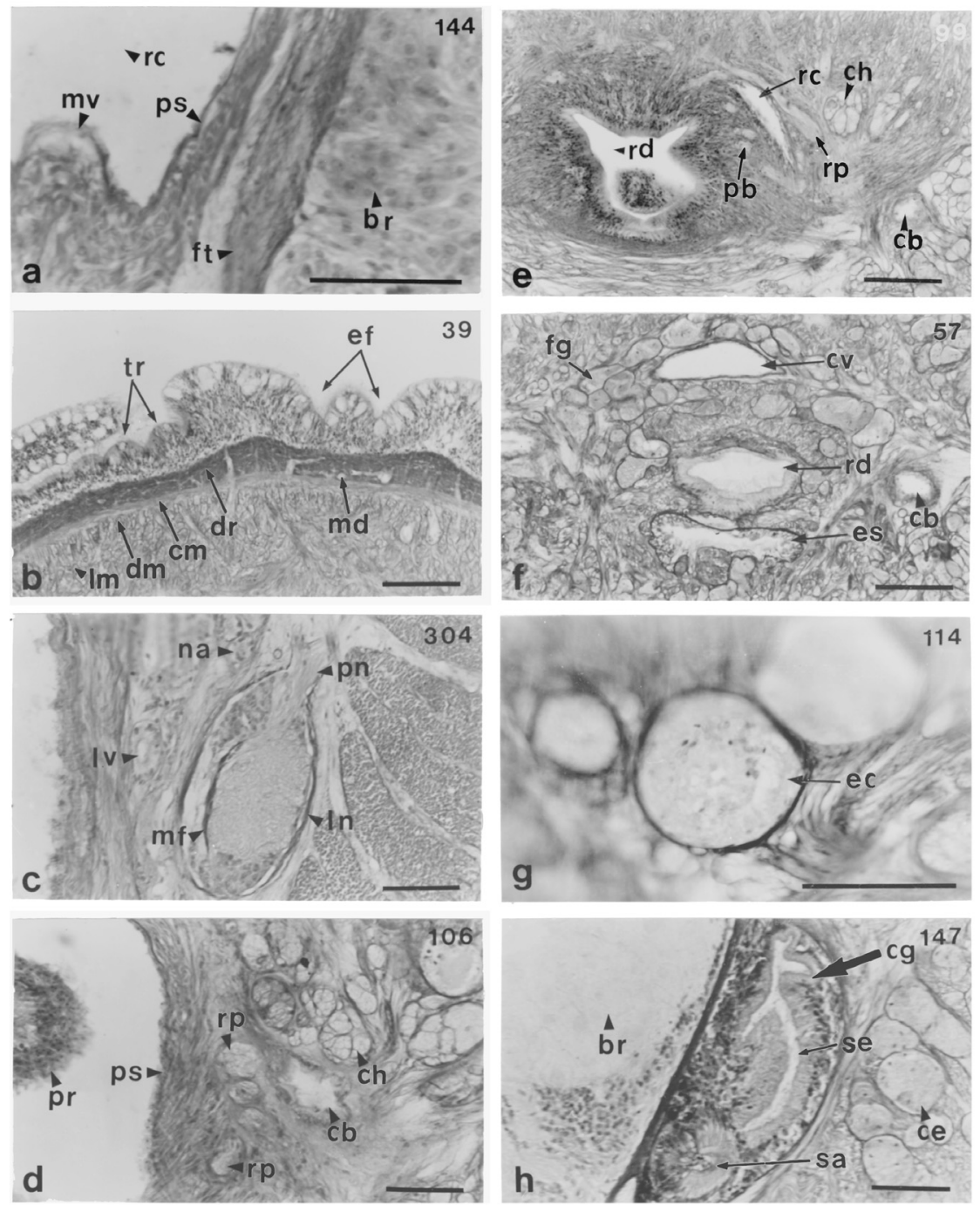

Fig. 17. Nipponnemertes punctatula. Transverse sections between 57-304 from the anterior end of the body (a-h), showing (a) fibrous connective tissue of brain, (b) mid-dorsal nerve beyond the brain, two epidermal folds, and transverse ridges of the secondary grooves, (c) myofibrilla and peripheral nerves of the lateral nerve cord, (d) four nerves from a proboscis nerve trunk arising from the anterior end of each ventral ganglion, (e) proboscis nerves entered into the proboscis, rhynchocoel, and proboscis sheth, (f) frontal glands around the cephalic anastomosis of blood vessel, (g) eye of inverted pigment-cup type, (h) sensory canal and slender sac of cerebral sensory organ. Scale $50 \mu \mathrm{m}(\mathrm{a}, \mathrm{c}-\mathrm{e}, \mathrm{g}, \mathrm{h})$ and $100 \mu \mathrm{m}(\mathrm{b}, \mathrm{f}) . \mathrm{br}=\mathrm{brain} ; \mathrm{cb}=$ cephalic blood vessel; $\mathrm{ce}=$ cephalic glands; $\mathrm{cg}=$ cerebral sensory organ; $\mathrm{ch}=$ cephalic nerve; $\mathrm{cm}=$ circular muscle layer of body wall; $\mathrm{cv}=$ cephalic anastomosis of blood vessel; $\mathrm{dm}=$ diagonal muscle layer; $\mathrm{dr}=$ dermis; ec = eye; ef = epidermal fold; es = esophagus; $\mathrm{fg}=$ frontal glands; $\mathrm{ft}=$ fibrous connective tissue of brain; $1 \mathrm{~m}=$ longitudinal muscle layer of body wall; $l \mathrm{ln}=$ lateral nerve cord; $1 \mathrm{v}=$ lateral blood vessel; $\mathrm{md}=$ middorsal nerve $; \mathrm{mf}=$ myofibril; $\mathrm{mv}=$ median vascular plug; $\mathrm{na}=$ nephridia; $\mathrm{pb}=$ proboscis nerve; $\mathrm{pn}=$ peripheral nerve; $\mathrm{pr}=$ proboscis; $\mathrm{ps}=$ proboscis sheath; $\mathrm{rc}=$ rhynchocoel; $\mathrm{rd}=$ rhynchodeum; $\mathrm{rp}=$ rudiment of proboscis nerve; $\mathrm{sa}=$ sensory canal; $\mathrm{se}=\mathrm{sac}$ of cerebral sensory organ; $\mathrm{tr}$ $=$ transverse ridges of secondary grooves. 

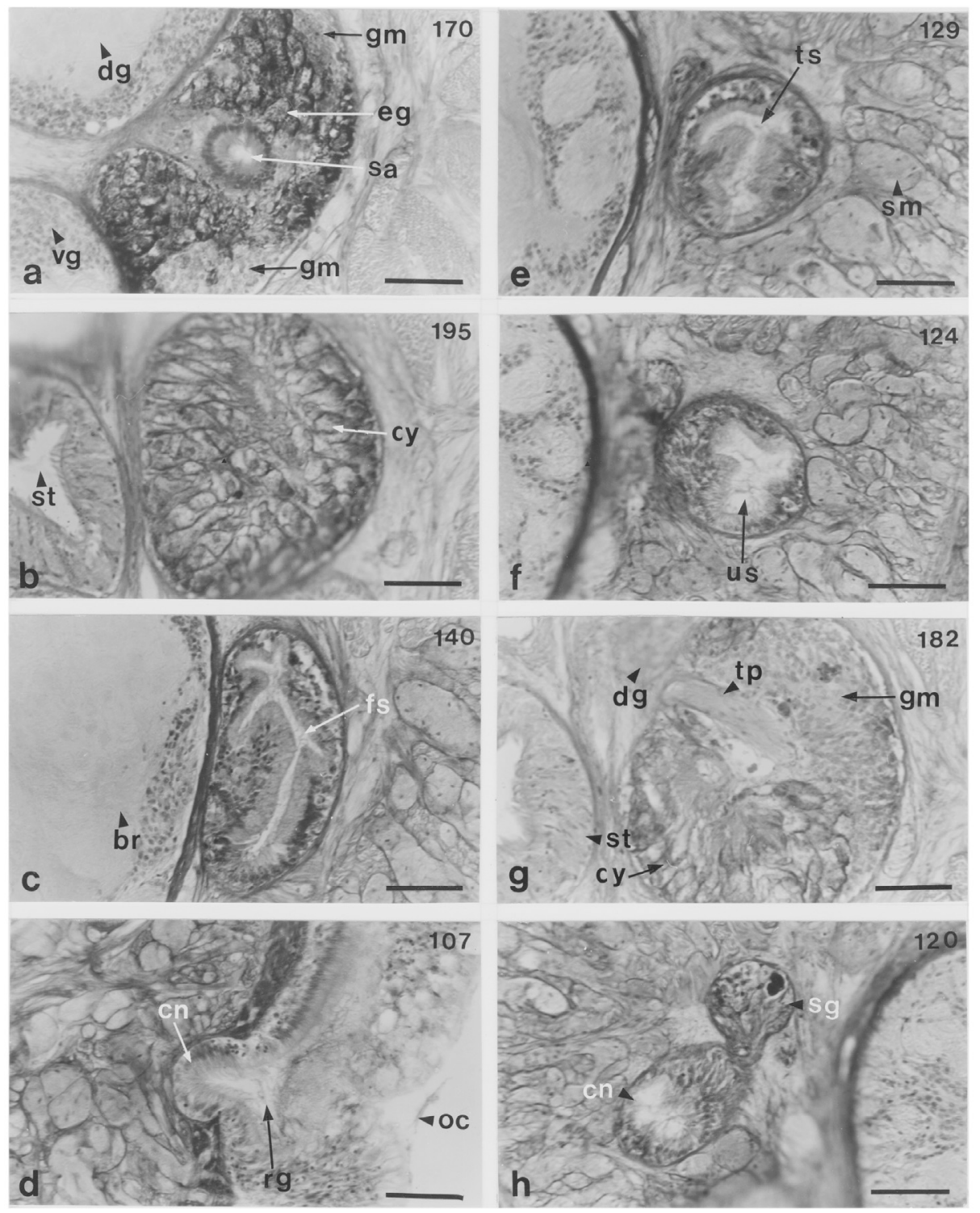

Fig. 18. Nipponnemertes punctatula. Transverse sections between 107-195 from the anterior end of the body, showing (a) eosinophilic glandular mass behind the sac of the cerebral sensory organ and ganglionic mass of cerebral sensory organ, (b) cyanophilic glandular mass behind the sensory canal, (c) six narrow furrows formed in the wall of the sac, (d) opening of cerebral sensory organ, (e) T-shaped portion of cerebral sensory organ, (f) U-shaped ciliated sensory portion of cerebral sensory organ, (g) thick nerve from the posterior end of the dorsal ganglion, (h) glandular mass of cerebral organ canal. Scale $50 \mu \mathrm{m}(\mathrm{a}-\mathrm{h})$. br $=$ brain; $c e=$ cephalic glands; $\mathrm{cn}=$ cerebral organ canal; $\mathrm{cy}=$ cyanophilic glandular mass; $\mathrm{dg}=\mathrm{dorsal}$ ganglion; eg = eosinophilic glandular mass; fs = furrow of the sac of cerebral sensory organ; gm = ganglionic mass; oc = opening of cerebral organ; $\mathrm{ps}=$ proboscis sheath; $\mathrm{rg}=$ cephalic groove (right side); $\mathrm{sa}=$ sensory canal; $\mathrm{sg}=$ small glandular mass; $\mathrm{sm}=$ subepithelial glands; $\mathrm{st}=$ stomach; $\mathrm{tp}=$ thick nerve from dorsal ganglion; $\mathrm{ts}=\mathrm{T}$-shaped portion of cerebral sensory organ; $\mathrm{us}=\mathrm{U}$-shaped ciliated sensory portion of cerebral sensory organ; $\mathrm{vg}=$ ventral ganglion. 
the cerebral ganglia; it is covered by fibrous connective tissue. The cerebral organ canal, located at the anterior end of the cerebral sensory organ, branches into a sensory canal on its ventral side and a dorsally-located slender sac with two kinds of glandular masses (Fig. 17h); the glandular mass behind the sac is eosinophilous, while that of the sensory canal is cyanophilous (Fig. 18a, b). The sac has a thick $(20 \mu \mathrm{m})$ ciliated wall containing sensory cells in the outer marginal portion. One to six narrow furrows are evident in the wall of the sac (Fig. 18c). The U-shaped ciliated sensory portion and the Tshaped portion are recognizable behind the cerebral organ canal (Fig. 18d-f) (cf. Iwata, 2001). Anteriorly, the organ is cylindrical in transverse section, but farther posteriorly it becomes oval (Fig. 18a). Its posterior glandular portion is also cylindrical (Fig. 18b). The thick nerve from the posterior end of the dorsal ganglion enters the posterior portion of the glandular mass of the sac (Fig. 18g). The ganglionic mass of the cerebral sensory organ is confined to the middle portion of the organ, extending antero-posteriorly to the nerve from the dorsal ganglion. A small glandular mass is connected with the cerebral organ canal, as shown in Fig. 16g (right side) and Fig. 18h (left side). Glands are lacking at the bifurcation of the canal.

\section{Excretory and reproductive system}

The excretory tubules extend from the level of the posterior portion of the cerebral sensory organ to the level of the posterior end of the pylorus. The two efferent ducts, originating in the anterior portion of the nephridial region, are long ( $24 \mu \mathrm{m}$ long) and run dorsal to the lateral nerve cords, opening on the lateral side of the body. The female gonads of the specimen are immature.

\section{Systematic discussion}

The present specimen of Nipponnemertes punctatula (female) shows four especially important characters: (1) The rhynchodeum has, between the anterior end of the head and the precerebral septum of the proboscis, two widenings of its cavity; (2) the esophagus has a thin platelike horizontal sheet between the rhynchodeum and the esophagus; (3) in the head region, there is a muscular plate of circular muscle between the rhynchodeal sphincter and the esophagus; (4) the rhynchocoel in front of the brain has a horizontal bundle of circular muscle.

This nemertean differs slightly from the California form of the same species in having of a cephalic furrow with sagittally-ridged secondary grooves; a pear-shaped basis of the central stylet; number of the proboscis nerves, 12 or 13 in the California form, while 12 or 16 in San Juan form; and a weakly developed inner circular muscle layer around the anus. Amphiporus nebulosus Coe is similar to the present species in external characters and markings of the body, but quite distinct in internal characters, such as extra-cerebral vessels in front of the brain and glandular tissues in the body-wall longitudinal muscle layer. Amphiporus angulatus japonicus resembles the present species in the markings on the head.

\section{Acknowledgements}

I thank Prof. Dr. A. O. Dennis Willows, former Director of Friday Harbor Laboratories, University of Washington, and Dr. Kenneth P. Sebens, present Director, for providing facilities for research. Prof. Dr. Eugene Kozloff, also of Friday Harbor Laboratories, helped by reviewing the manuscript. Finally, the comments and suggestions of Prof. Dr. Yoshihisa Shirayama, Director of Seto Marine Biological Laboratory, Kyoto University and the help of two anonymous reviewers are also appreciated. The study was supported in part by a NSF Grant, USA in 1964.

\section{References}

Berg, G. 1972. Taxonomy of Amphiporus lactifloreus (Johnston, 1828) and Amphiporus dissimulans Riches, 1893 (Nemertini, Hoplonemertini). Astarte, 5,19-26.

Coe, W.R. 1901. Papers from the Harriman Alaska Expedition. XX. The nemerteans. Proceedings of the 
Washington Academy of Sciences, 3, 1-110.

Coe, W.R. 1904. Nemerteans of the Pacific coast of North America. Part II. Harriman Alaska Series. II, 111-220.

Coe, W.R. 1905. Nemerteans of the west and northwest coasts of America. Bulletin of the Museum of Comparative Zoology at Harvard College, 47,1-319.

Correa, D.D. 1964. Nemerteans from California and Oregon. Proceedings of the California Academy of Sciences, Series 4, 31, 515-558.

Crandall, F.B. 2001. A cladistic view of the Monostilifer (Hoplonemertea) with Interwoven rhynchocoel musculsture: a preliminary assessment. Hydrobiologia, 456, 87-110.

Friedrich, H. 1968. Sagaminemertes, eine bemerkenswerte neue Gattung der Hoplonemertinen und ihre systematische Stellung. Zoologischer Anzeiger, 180, 33-36.

Gibson, R. 1982a. Nemertea, in S. P. Parker (ed): Synopsis and Classification of Living Organisms (New York: McGraw-Hill), 1, 823-846.

Gibson, R. 1982b. British Nemerteans (No. 24 in Synopses of the British Fauna, New Series, eds D. M. Kermack and R. S. K. Barnes) (Cambridge: University Press), 212 pp.

Gibson, R. 1985. The need for a standard approach to taxonomic descriptions of nemerteans. American Zoologist, 25, 5-14.

Gibson, R. 1995. Nemertean genera and species of the world: an annotated checklist of original names and description citations, synonyms, correct taxonomic status, habitats and recorded zoogeographic distribution. Journal of Natural History, 29, 271-562.

Gibson, R. and Crandall F.B. 1989. The genus Amphiporus Ehrenberg (Nemertea, Enopla, Monostiliferoidea). Zoologica Scripta, 18, 453-470.

Gibson, R. and Crandall, F.B. 1991. Amphiporus Ehrenberg, 1831 (Nemertea): Proposed designation of Planaria lacriflorea Johnston, 1828 as the type species. Bulletin of Zoological Nomenclature, 48, 22-24.

Gibson, R. and Sundberg, P. 1992. Three new nemerteans from Hong Kong. The marine flora and fauna of Hong Kong and southern China III (ed. B. Morton). Proceedings of the Fourth International Marine Biological Workshop: The Marine Flora and Fauna of Hong Kong and Southern China, Hong Kong, 11-29 April 1989. Hong Kong: Hong Kong University Press, 1992, 97-129.

Griffin, B.B. 1898. Description of some marine nemerteans of Puget Sound and Alaska. Annals of the New York Academy of Sciences, 11, 193-217.

Iwata, F. 1951. Nemerteans in the vicinity of Onomichi. Journal of the Faculty of Science, Hokkaido Unversity, Series 6, Zoology, 10, 135-138.

Iwata, F. 1952. Nemertini from the coasts of Kyusyu. Journal of the Faculty of Science, Hokkaido University, Series 6, Zoology, 11, 144-146.

Iwata, F. 1954a. Some nemerteans from the coasts of the Kii Peninsula. Publications of the Seto Marine Biological Laboratory, 4, 33-42.

Iwata, F. 1954b. The fauna of Akkeshi Bay. XX. Nemertini in Hokkaido. Journal of the Faculty of Science, Hokkaido University, Series 6, Zoology, 12, 1-39.

Iwata, F. 1957. Nemerteans from Sagami Bay. Publications from the Akkeshi Marine Biological Station, 7, 1-31.

Iwata, F. 2001. Nipponnemertes fernaldi, a new species of swimming monostiliferous hoplonemertean from the San Juan Archipelago, Washington, USA. Proceedings of the Biological Society of Washington, 114, 833857.

Norenburg, J. 1986. Redescription of a brooding nemertean, Cyanophthalma obscura (Schultze) gen. et comb. n., with observations on its biology and discussion of the species of Prostomatella and related taxa. Zoologica Scripta, 15, 275-273.

Punnett, R.C. 1901. On some Arctic nemerteans. Proceedings of the Zoological Society of London, 2, 90-107.

Takakura, U. 1898. Classification of Nemertini in the vicinity of Misaki. Zoological Magazine, 10, 38-44, 116120, 184-187, 331-337, 424-429. (in Japanese)

Thollesson, M. and J.L. Norenburg. 2003. Ribbon worm relationships: a phylogeny of the phylum Nemertea. Proceedings of the Royal Society, London B, 270, 407-415.

Yamaoka, T. 2005. On fourteen monostiliferous hoplonemerteans from the Izu Peninsula, Middle Japan. Publications of the Seto Marine Biological Laboratory, 40, 141-158. 


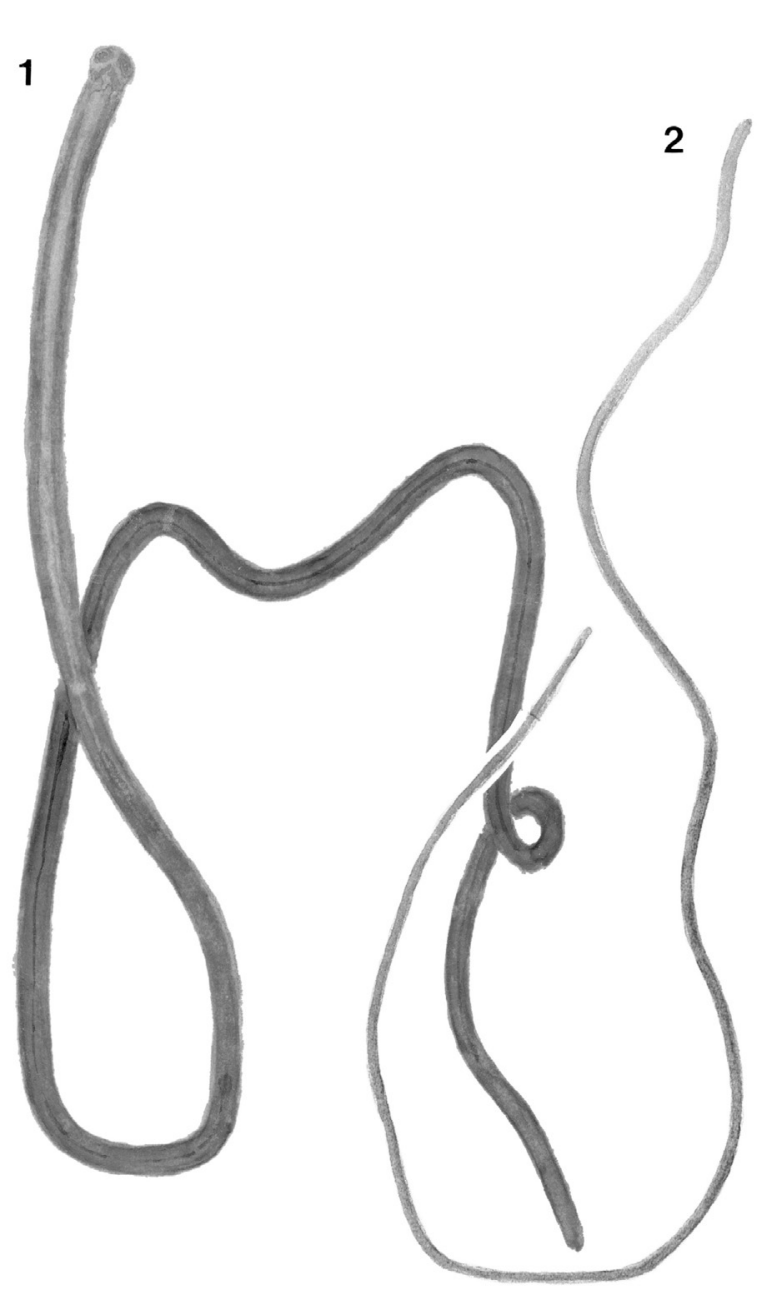

\section{3}

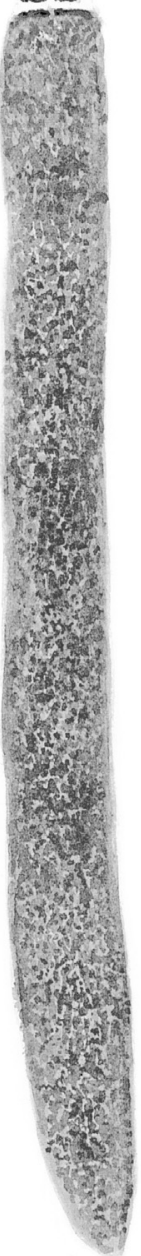

4

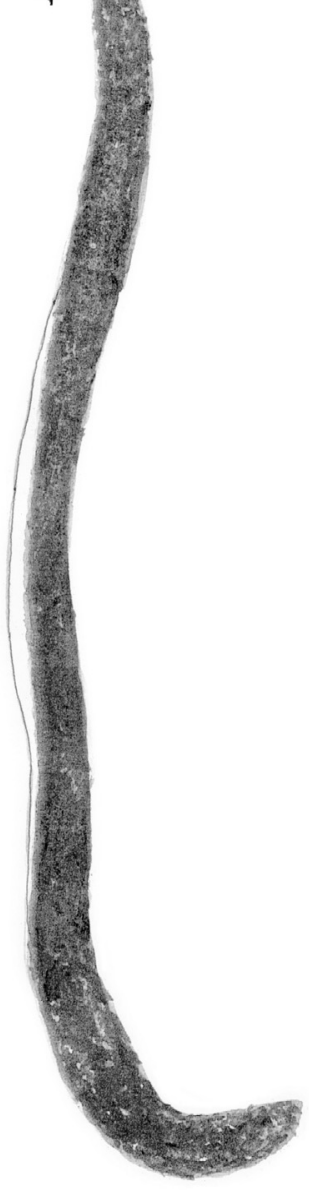

\section{Explanation of Plate 1.}

All sketches, drawn in 1964, are dorsal views.

Fig. 1. Amphiporus formidabilis Griffin.

Fig. 2. Amphiporus imparispinosus Griffin.

Fig. 3. Nipponnemertes punctatula (Coe).

Fig. 4. Nipponnemertes punctatula (Coe). 